\title{
Semi-empirical relationships to assess the seismic performance of slopes from an updated version of the Italian seismic database
}

\author{
D. Gaudio ${ }^{1,2} \mathbb{E} \cdot$ R. Rauseo $^{1} \cdot$ L. Masini ${ }^{1}$ (D) $\cdot$ S. Rampello ${ }^{1}$ (D)
}

Received: 9 April 2020 / Accepted: 16 August 2020 / Published online: 28 August 2020

(C) The Author(s) 2020

\begin{abstract}
Seismic performance of slopes can be assessed through displacement-based procedures where earthquake-induced displacements are usually computed following Newmark-type calculations. These can be adopted to perform a parametric integration of earthquake records to evaluate permanent displacements for different slope characteristics and seismic input properties. Several semi-empirical relationships can be obtained for different purposes: obtaining site-specific displacement hazard curves following a fully-probabilistic approach, to assess the seismic risk associated with the slope; providing semi-empirical models within a deterministic framework, where the seismic-induced permanent displacement is compared with threshold values related to different levels of seismic performance; calibrating the seismic coefficient to be used in pseudo-static calculations, where a safety factor against limit conditions is computed. In this paper, semi-empirical relationships are obtained as a result of a parametric integration of an updated version of the Italian strongmotion database, that, in turn, is described and compared to older versions of the database and to well-known ground motion prediction equations. Permanent displacement is expressed as a function of either ground motion parameters, for a given yield seismic coefficient of the slope, or of both ground motion parameters and the seismic coefficient. The first are meant to be used as a tool to develop site-specific displacement hazard curves, while the last can be used to evaluate earthquake-induced slope displacements, as well as to calibrate the seismic coefficient to be used in a pseudo-static analysis. Influence of the vertical component of seismic motion on these semi-empirical relationships is also assessed.
\end{abstract}

Keywords Italian seismic database $\cdot$ Permanent displacement $\cdot$ Semi-empirical relationship $\cdot$ Pseudo-static approach $\cdot$ Seismic coefficient $\cdot$ Slope

D. Gaudio

dg564@cam.ac.uk

Extended author information available on the last page of the article 


\section{Introduction}

Stability of a slope subjected to seismic loading depends on slope and earthquake characteristics. Attainment of limit conditions can be mainly ascribed to seismic-induced inertial forces acting in the unstable mass and/or to a decrease of the shear strength induced by pore water pressure build-up (Di Filippo et al. 2019) and cyclic degradation of shear strength parameters (Bandini et al. 2015). Inertial forces induce permanent displacements accumulating until the end of the seismic event, while a decrease in the shear strength can result in slope collapse occurring in post-seismic conditions.

Focusing on the effects of seismic-induced inertial forces, seismic performance of slopes can be assessed in terms of the permanent displacement attained at the end of the seismic event, through dynamic analyses (Rathje and Cho 2019), displacement-based analyses (Ji et al. 2020) and either limit-equilibrium (Saade et al. 2016) or limit-analysis (Ausilio et al. 2000) force-based computations. These methods primarily differ in complexity and in the representation of the seismic action. While dynamic analyses can be quite complex and time-consuming, in limit-equilibrium analyses seismic-induced inertial forces are reproduced in a quite crude fashion through the pseudo-static approach. Hence, the well-known displacement-based Newmark's method (1965) can be deemed a good compromise both in terms of accuracy and complexity, particularly for shallow sliding surfaces, for which the assumption of rigid behaviour is typically adequate. In contrast, in the presence of deep sliding surfaces deformabililty of the unstable soil mass should be considered (Rathje and Antonakos 2011; Tsai and Chien 2016).

After parametrically integrating a set of acceleration time histories, several empirical relationships based on the Newmark's method are available in the literature. Using these models, the seismic performance of a slope can be estimated through the permanent displacements induced by earthquake loading, computed as a function of some ground motion parameters and the slope yield seismic coefficient $k_{\mathrm{y}}$ (Saygili and Rathje 2008; Fotopoulou and Pitilakis 2015): this latter is the seismic coefficient for which the pseudo-static factor of safety $\left(F_{\mathrm{S}}\right)$ of a given slope is equal to unity. The models mainly differ in the adopted seismic database and in the selected functional form. These semi-empirical relationships are typically used to develop site-specific displacement hazard curves when a fully-probabilistic approach is followed (Rathje and Saygili 2011; Rathje et al. 2014; Du and Wang 2016; Macedo et al. 2018; Wang and Rathje 2018; Macedo and Candia 2020). In this approach, the aleatory variability of both ground motion properties and resulting displacements is explicitly taken into account. However, due to the inherent complexity of this procedure, these variabilities are typically neglected or not treated rigorously, thus following either a deterministic or a semi-probabilistic approach (Rathje and Saygili 2008), as already done in several studies (e.g. Jibson 2007) when a screen analysis (Stewart et al. 2003 ) is meant to be performed. Much more frequently adopted in common practice is the pseudo-static approach, where the inertial forces acting in the slope are represented via constant static-equivalent forces proportional to the self-weight of the unstable mass through the seismic coefficient $k$. In the framework of the performance-based design, the seismic coefficient can be calibrated against the seismic performance desired for the slope, typically expressed in terms of threshold permanent displacements, $d_{\mathrm{y}}$. This procedure has been widely adopted in the literature for applications to slopes (Bray and Travasarou 2009; Rampello et al. 2010; Biondi et al. 2011; Bray et al. 2017), earth dams (Seed 1979; HynesGriffin and Franklin 1984), solid-waste landfills (Bray et al. 1998), hillside residential and commercial developments (Stewart et al. 2003), mountain reservoirs (Veylon et al. 2017) 
and retaining walls (Biondi et al. 2014; Gaudio et al. 2018a, b, 2021). In this approach, the seismic performance of the slope is still evaluated applying the force-based pseudo-static approach, in which the equivalent seismic coefficient $k$ is the critical seismic coefficient that corresponds to a threshold or limit displacement $d_{\mathrm{y}}$.

In this paper, well-known semi-empirical relationships are updated by performing a parametric integration of a new version of the Italian seismic database, this covering the time frame 1972-2017 and thus including the seismic records of recent destructive seismic events (2009 L’Aquila, Maugeri et al. 2011; 2012 Emilia, Mucciarelli and Liberatore 2014, de Nardis et al. 2014; and 2016 Central Italy seismic sequences, Mollaioli et al. 2018; Luzi et al. 2019).

The article is organised as follows. The main characteristics and the most significant ground motion parameters of the new Italian seismic database are firstly presented and compared to those obtained in a previous version of the database (SISMA 2008; Scasserra et al. 2008) and to the ones computed with widely-used ground motion prediction equations (GMPEs). Then, semi-empirical models for predicting permanent displacements are developed. One (scalar) and two (vector) ground motion parameter empirical models are obtained, adapting the ones recently proposed by Rathje and Cho (2019) to the Italian seismicity. Furthermore, upper-bound semi-empirical relationships are derived, in the functional form proposed by Ambraseys and Menu (1988), thus linking permanent displacements $d$ to the ratio between the yield and the maximum seismic coefficient, $k_{\mathrm{y}} / k_{\max }$, where $k_{\max }=P G A / g$ and $P G A$ is the peak ground acceleration. Influence of the vertical component of seismic motion on these relationships is also assessed. The seismic coefficient $k$, used in pseudo-static calculations, is therefore computed for given threshold values of permanent displacements $d_{\mathrm{y}}$ assuming different subsoil classes and acceleration levels. Different semi-empirical relationships are finally provided where permanent displacements $d$ are expressed as a function of other ground motion parameters in addition to the ratio $k_{\mathrm{y}} / k_{\max }$, such as $P G A$, the mean period $T_{\mathrm{m}}$, the significant duration $D_{5-95}$ (Tropeano et al. 2017) and the Arias intensity $I_{\mathrm{A}}$ (Jibson 1993, 2007; Chousianitis et al. 2014), identifying the most convenient models to evaluate earthquake induced displacements.

The results of this study can be mainly used for hazard mapping or to perform screen analyses (Stewart et al. 2003) for slopes located on the national territory based on an updated version of the Italian seismic database.

\section{Seismic database}

Accelerometric records used in this study are referred to a time window between 14/06/1972 and 27/04/2017. Records related to the period 14/06/1972 to 31/12/2015 were extracted from the database ITACA (ITalian ACcelerometric Archive v.2.1, Luzi et al. 2016a) while those from 01/01/2016 to 27/04/2017 were obtained from the ESM database (Engineering Strong-Motion, Luzi et al. 2016b). This database, named ITACA + ESM_2017 in the following, includes 947 records of 207 seismic events with moment magnitude $M_{\mathrm{w}} \geq 4$, peak ground accelerations $P G A \geq 0.05 \mathrm{~g}$, epicentral distance $R_{\mathrm{ep}}<100 \mathrm{~km}$, and focal depth $z_{\mathrm{ip}} \leq 45 \mathrm{~km}$, recorded by 297 stations located throughout the national territory.

Values of the local magnitude $M_{\mathrm{L}}$ are available for 203 seismic events, while the moment magnitude $M_{\mathrm{w}}$ is known for 141 events. Epicentral distance $R_{\mathrm{ep}}$ and focal depth $z_{\mathrm{ip}}$ are known for all records, while Joyner and Boore distance, $R_{\mathrm{JB}}$, (Joyner and Boore 1981) is known for 309 records. For the records with magnitude greater than 6 , Joyner and Boore 
distance $R_{\mathrm{JB}}$ was computed through the empirical relationship proposed by Malagnini and Montaldo (2004), as a function of the epicentral distance $R_{\mathrm{ep}}$ :

$$
R_{\mathrm{JB}}=-3.5525+0.8845 \cdot R_{\mathrm{ep}}
$$

Since this relationship is valid for superficial magnitude $M_{\mathrm{s}} \geq 6$, that is not available, it was assumed $M_{\mathrm{s}}=M_{\mathrm{w}}$ according to Idriss (1985), thus using Eq. (1) for $M_{\mathrm{w}} \geq 6$.

Information about the subsoil class identified by the classification provided by Eurocode 8, Part 1 (CEN 2003) is available for each station. The subsoil class is attributed on the basis of the average shear wave velocity in the upper $30 \mathrm{~m}, V_{\mathrm{s}, 30}$, or, in the absence of such data, on surface geological categorisation (Felicetta et al. 2017). The records were divided into five groups: rock or rock-like subsoil, with $V_{\mathrm{s}, 30}>800 \mathrm{~m} / \mathrm{s}$ (class A), dense granular and stiff cohesive subsoil, with $V_{\mathrm{s}, 30}=360-800 \mathrm{~m} / \mathrm{s}$ (class B), medium dense granular and medium stiff cohesive subsoil, with $V_{\mathrm{s}, 30}=180-360 \mathrm{~m} / \mathrm{s}$ (class C), loose granular and soft cohesive subsoil, with $V_{\mathrm{s}, 30}<180 \mathrm{~m} / \mathrm{s}$ (class D) and subsoils with $V_{\mathrm{s}}$ values of class C or D and thickness of 5 to $20 \mathrm{~m}$ underlain by stiffer material with $V_{\mathrm{s}}>800 \mathrm{~m} / \mathrm{s}$ (class E). When only geological data were available, subsoil categories were identified by symbols $\mathrm{A}^{*}, \mathrm{~B}^{*}$, $C^{*}, D^{*}, E^{*}$. About $13 \%$ of the records (123) were attributed to subsoil class A, 49.5\% (469) to subsoil class B, $31 \%$ (294) to subsoil class C, $1.5 \%$ (14) to subsoil D, and $5 \%$ (47) to subsoil E. Due to the scarce number of records assigned to subsoil classes D and E, these were considered as a single subsoil group together with subsoil class $\mathrm{C}$, as already done in previous works (e.g. Rampello et al. 2010), and identified as soft soils in the following.

The database provides three acceleration time histories for each record: two horizontal components, related to the North-South and East-West directions, and one vertical component, relative to the Up-Down direction.

Characteristics of the database are described in Table 1 and in Figs. 1, 2 and 3: these were obtained by processing all the records as well as using the ESM-flatfile_2017 (Lanzano et al. 2017). Ground motion parameters describing both horizontal and vertical acceleration time histories are given in the Appendix 1. For each subsoil class, Table 1 shows the minimum and maximum magnitudes $M$, the focal depth $z_{\text {ip }}$ and

Table 1 Parameters of the seismic events considered in this study

\begin{tabular}{lrrrlllllll}
\hline Subsoil class & $n . r e g$ & \multicolumn{1}{c}{$M_{\mathrm{L}}$} & \multicolumn{1}{c}{$M_{\mathrm{W}}$} & $z_{\text {ip }}(\mathrm{km})$ & $R_{\text {ep }}(\mathrm{km})$ & $T F$ & $N F$ & $S S$ & $U$ & $n . a$ \\
\hline$A$ & 13 & $4.1-6.5$ & $4.1-6.9$ & $4.3-22.1$ & $1.4-36.9$ & 1 & 10 & 1 & 1 & \\
$A^{*}$ & 110 & $4-6.1$ & $4-6.5$ & $0.9-30$ & $0.7-89.9$ & 1 & 83 & 11 & 15 & \\
$A+A^{*}$ & 123 & $4-6.5$ & $4-6.9$ & $0.9-30$ & $0.7-89.9$ & 2 & 93 & 12 & 16 & \\
$B$ & 150 & $3.6-6.5$ & $4-6.9$ & $3-45$ & $1.2-78.4$ & 33 & 95 & 9 & 13 & \\
$B^{*}$ & 319 & $3-6.1$ & $4-6.5$ & $1-24.5$ & $0.6-90.4$ & 13 & 238 & 15 & 48 & 5 \\
$B+B^{*}$ & 469 & $3-6.5$ & $4-6.9$ & $1-45$ & $0.6-90.4$ & 46 & 333 & 24 & 61 & 5 \\
$C$ & 54 & $3.7-6.4$ & $4.5-6.5$ & $3-29$ & $2.8-95.3$ & 25 & 14 & 8 & 7 & \\
$C^{*}$ & 240 & $4-6.4$ & $4-6.5$ & $0.9-30$ & $0.4-81.5$ & 97 & 95 & 11 & 37 & \\
$C+C^{*}$ & 294 & $3.7-6.4$ & $4-6.5$ & $0.9-30$ & $0.4-95.3$ & 122 & 109 & 19 & 44 & \\
$D$ & 14 & $3.7-6.1$ & $4.3-6.5$ & $0.9-9.2$ & $2.4-50.3$ & & 9 & 5 & & \\
$E$ & 47 & $4-6.1$ & $4.2-6.5$ & $0.1-14$ & $1.3-73.9$ & & 37 & 5 & 5 & \\
All & 947 & $3-6.5$ & $4-6.9$ & $0.1-45$ & $0.4-95.3$ & 170 & 581 & 65 & 126 & 5 \\
\hline
\end{tabular}

n.reg.: number of registrations; $T F$ : reverse fault, $N F$ : normal fault, $S S$ : strike-slip fault, $U$ : oblique reverse fault, n.a.: not available 

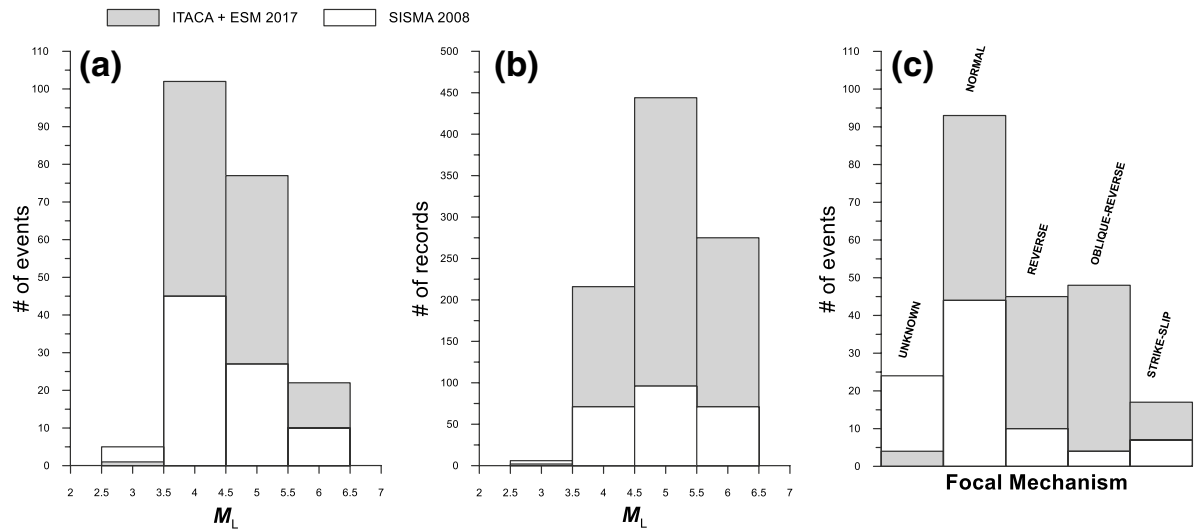

Fig. 1 Comparison between SISMA 2008 and ITACA +ESM_2017. Distribution of: a number of events and b records versus local magnitude; c number of events versus focal mechanism
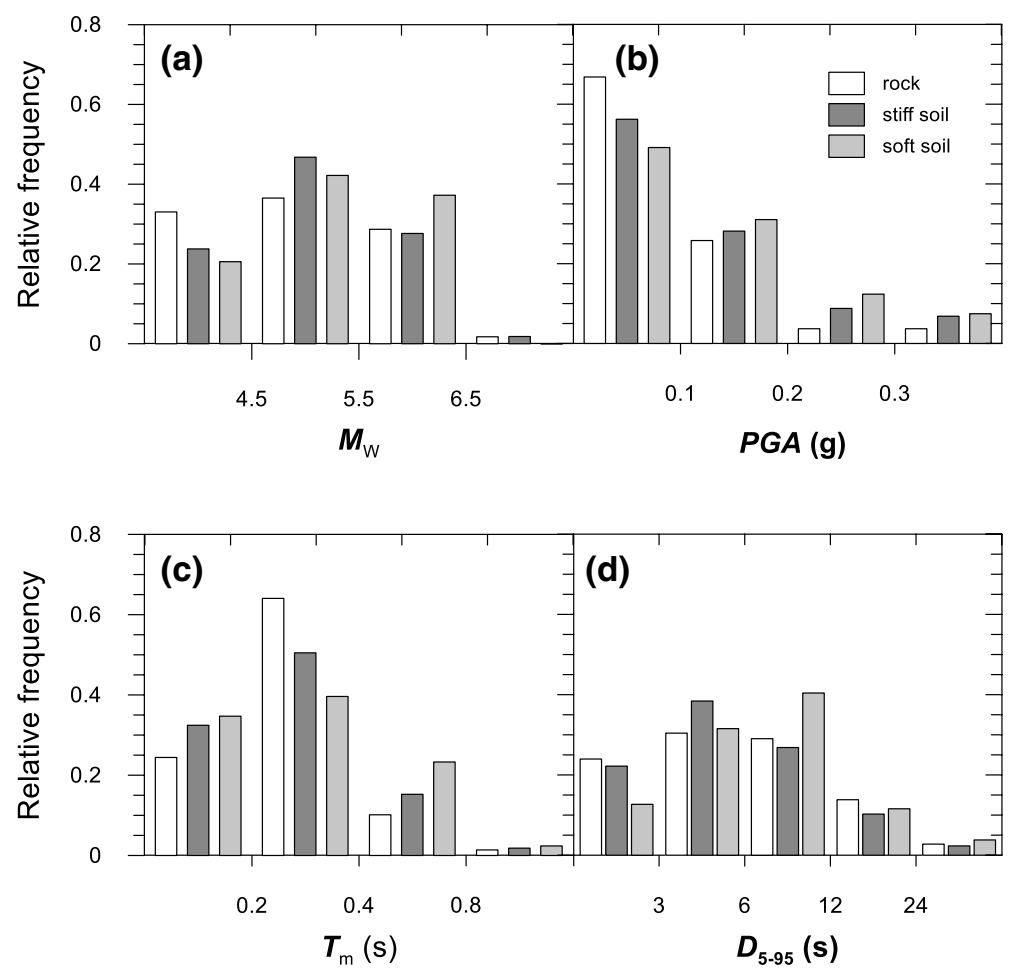

Fig. 2 Frequency distribution of: a moment magnitude, $\mathbf{b}$ peak ground acceleration, $\mathbf{c}$ mean period, and $\mathbf{d}$ significant duration

the focal mechanism of the seismic events. Values of local magnitude $M_{\mathrm{L}}=3$ to 6.5 , moment magnitude $M_{\mathrm{w}}=4$ to 6.9 are obtained for all subsoil classes with a maximum focal depth $z_{\mathrm{ip}}=45 \mathrm{~km}$ and an epicentral distance $R_{\mathrm{ep}}=95.3 \mathrm{~km}$. Most registrations 

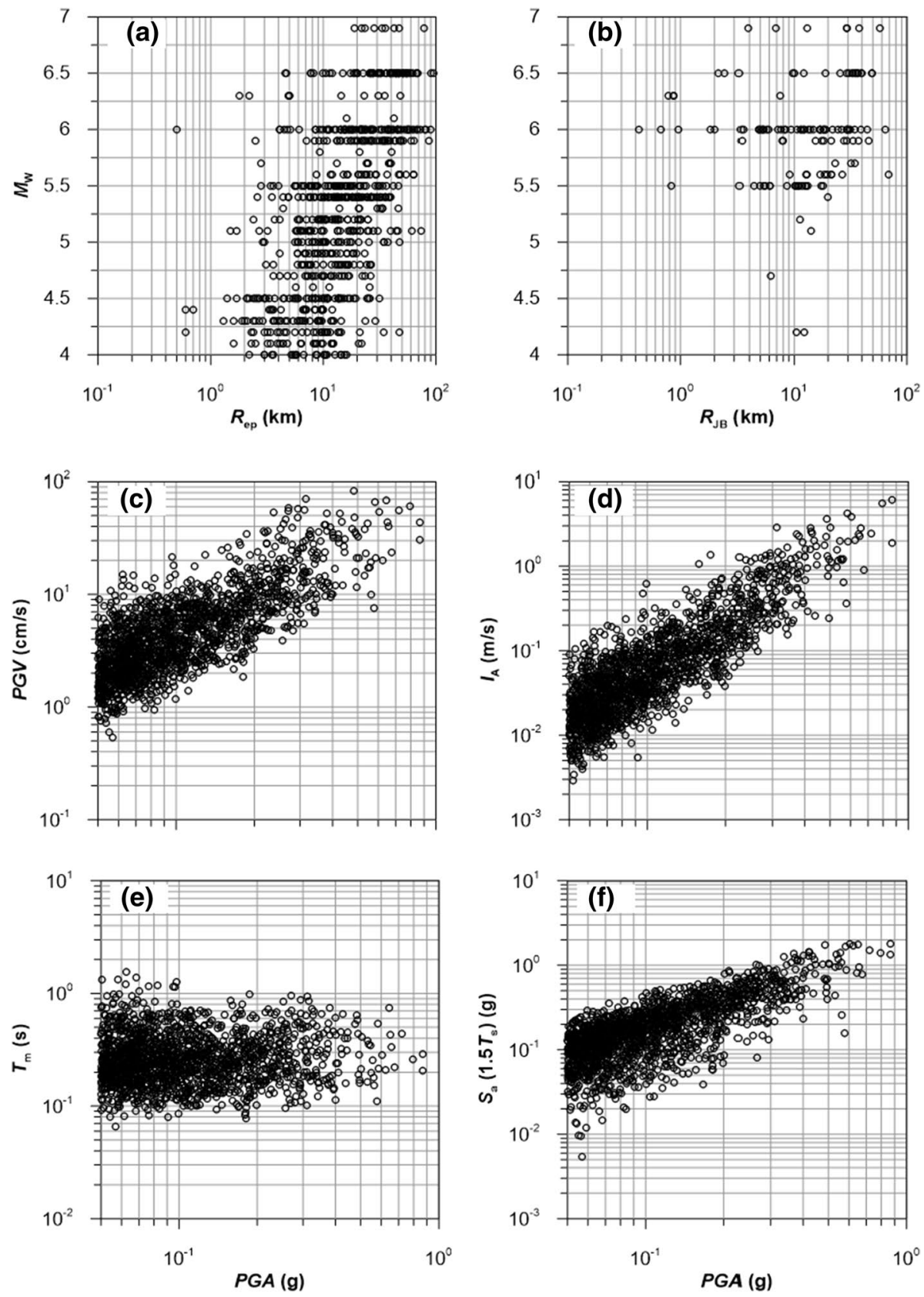

Fig. 3 Ground motion characteristics of the updated seismic database: $\mathbf{a}, \mathbf{b}$ moment magnitude, $\mathbf{c}$ peak ground velocity, $\mathbf{d}$ Arias intensity, e mean period, and $\mathbf{f}$ spectral acceleration at $1.5 T_{\mathrm{s}}$

(581, 61.3\%) are characterised by a normal focal mechanism (NF), while the registrations with reverse (TF), oblique reverse (U) and strike-slip (SS) fault mechanisms are 
$170(18 \%), 126(13.3 \%)$ and $65(6.9 \%)$, respectively. Focal mechanism is not available for $5(0.5 \%)$ registrations.

Figure 1 shows the distribution of the number of events (a) and records (b), as a function of the local magnitude $M_{\mathrm{L}}$, and of the number of events as a function of the focal mechanism (c) for the ITACA +ESM_2017 and for the SISMA 2008 (Scasserra et al. 2008) databases, the latter including 247 records of 89 Italian seismic events recorded by 101 stations in the period 1972-2002. For the seismic databases mentioned above, the maximum number of events is obtained for local magnitude $M_{\mathrm{L}}$ in the range of 3.5 to 4.5 (102 for ITACA +ESM_2017 and 45 for SISMA), while the maximum number of records is obtained for $M_{\mathrm{L}}=4.5-5.5$ (444 for ITACA +ESM_2017 and 96 for SISMA).

As expected, the number of seismic events and records of ITACA + ESM_2017 database is higher than the one of SISMA database, except for lower local magnitudes $M_{\mathrm{L}}=2.5-3.5$, since ITACA +ESM_2017 database includes events with $M_{\mathrm{w}}>4$ only.

The relative frequency distribution of moment magnitude $M_{\mathrm{w}}$ (a), peak ground acceleration $P G A(\mathrm{~b})$, mean period $T_{\mathrm{m}}$ (c) and significant duration $D_{5-95}$ (d) of the $I T A C A+E S M \_2017$ database is shown in Fig. 2 for the three subsoil classes: rock-like (A), stiff (B) and soft soils (C, D, E). For all the three subsoil classes, modal moment magnitude is between 4.5 and 5.5 (Fig. 2a), typical of most aftershock records of the main Italian seismic sequences (Tropeano et al. 2017). For the horizontal acceleration time histories, the most frequent peak acceleration (Fig. 2b) falls between 0.05 and $0.1 \mathrm{~g}$, while the modal value of mean period $T_{\mathrm{m}}$ (Fig. 2c) is between 0.2 and $0.4 \mathrm{~s}$. Significant duration $D_{5-95}$ (Fig. 2d) shows the modal value between 3 and $6 \mathrm{~s}$ for the rock-like and the stiff subsoil classes, and between 6 and $12 \mathrm{~s}$ for soft subsoils.

In Fig. 3 the moment magnitude $M_{\mathrm{w}}$ is plotted against the epicentral (Fig. 3a) and Joyner and Boore (b) distances, while peak ground velocity $P G V(\mathrm{c})$, Arias intensity $I_{\mathrm{A}}(\mathrm{d})$, mean period $T_{\mathrm{m}}$ (e) and spectral acceleration $S \mathrm{a}\left(1.5 T_{\mathrm{s}}\right)$, computed at the degraded period $1.5 T_{\mathrm{s}}(\mathrm{f})$, are plotted against peak ground acceleration $P G A$. A fundamental period of the slope $T_{\mathrm{s}}=0.19 \mathrm{~s}$ was assumed to compare $S \mathrm{a}\left(1.5 T_{\mathrm{s}}\right)$ to the values recently presented by Rathje and Cho (2019). As expected, increasing values of peak ground velocity $P G V$, Arias intensity $I_{\mathrm{A}}$ and spectral acceleration $S \mathrm{a}\left(1.5 T_{\mathrm{s}}\right)$ are obtained for increasing $P G A$, while no remarkable influence on the mean period $T_{\mathrm{m}}$ is detected.

The most significant ground motion parameters were compared with attenuation curves obtained from widely used ground motion prediction equations (GMPEs). For the sake of brevity, only the figures related to the horizontal components of seismic motion recorded on stiff soils (subsoil class B) during strong earthquakes (magnitudes $M=5.5-6.9$ ) are shown in the following, unless otherwise specified.

The curves obtained from the GMPEs proposed by Sabetta and Pugliese (1996) (Fig. 4a) and Ambraseys et al. (2005) (Fig. 4b) are plotted in Fig. 4 together with the peak horizontal acceleration derived from the seismic records. In each graph, the median curves and median curves $\pm 1 / 2 \sigma$ of the GMPEs are plotted, where $\sigma$ is the standard deviation of the error. The curves proposed by Ambraseys et al. (2005) are given for three different focal mechanisms $\left(F_{\mathrm{N}}\right.$ for normal faulting earthquakes, $F_{\mathrm{T}}$ for thrust faulting earthquakes and $F_{\mathrm{O}}$ for odd faulting earthquakes). Points related to events whose Joyner and Boore distance is calculated through the empirical relationship proposed by Malagnini and Montaldo (2004) are represented in grey. It turned out that points belonging to the ITACA +ESM_2017 database can be reliably predicted by the attenuation laws. Specifically, $P G A$ values lay between the curves proposed by Sabetta and Pugliese (1996) for magnitudes $M=5-7$, except for 15 out of 144 (about 10\%) seismic events exceeding the curve $M=7$ for epicentral distances $R_{\mathrm{ep}} \geq 8 \mathrm{~km}$ and just 1 plotting below the $\mu-\sigma / 2$ curve with $M=5$. Similarly, most of the 

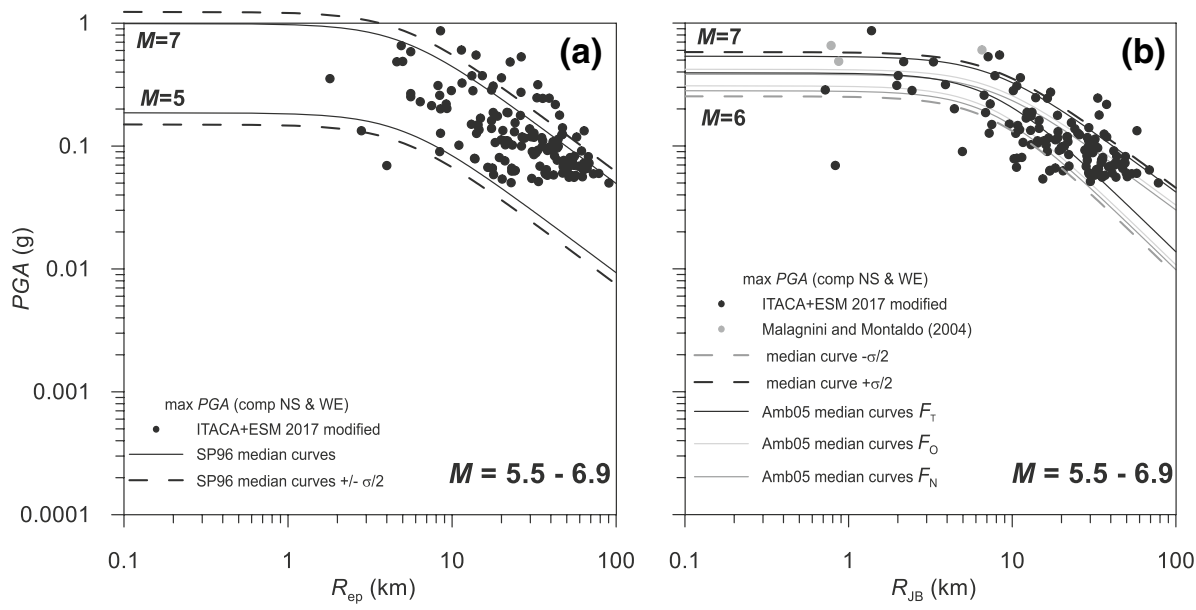

Fig. 4 Comparison between the peak ground horizontal accelerations recorded on stiff soils (ITACA + ESM_2017 database) and those computed using the GMPEs proposed by: a Sabetta and Pugliese (1996) and b Ambraseys et al. (2005)

points (105 out of 126, equal to the 83\%) representing the ITACA +ESM_2017 database plot between the curves proposed by Ambraseys et al. (2005) for magnitudes $M=6-7$, in the whole range of considered Joyner and Boore distances $\left(R_{\mathrm{JB}}=0.7-80 \mathrm{~km}\right)$ and particularly for high values of $R_{\mathrm{JB}}(\geq 20 \mathrm{~km})$. The reduced, but not negligible amount of data points plotting outside the range located by the attenuation laws, $10 \%$ and $17 \%$ with respect to Sabetta and Pugliese (1996) and Ambraseys et al. (2005), respectively, can be attributed to the different adopted databases: Sabetta and Pugliese (1996) referred to an old Italian database, Ambraseys et al. (2005) used a European database with $M_{\mathrm{w}} \geq 5$, while ITACA + ESM_2017 includes the most recent Italian seismic events.

Figure 5 shows the comparison between the attenuation laws proposed by Sabetta and Pugliese (1996) (Fig. 5a), Kayen and Mitchell (1997) (Fig. 5b) and the values of Arias intensity $I_{\mathrm{A}}$ derived from the records. Note that a different definition of $I_{\mathrm{A}}$ is adopted in the equation proposed by Sabetta and Pugliese (1996), as follows:

$$
I_{\mathrm{A}}=\int a(t)^{2} d t
$$

For the GMPE proposed by Sabetta and Pugliese (1996) the maximum Arias intensity of the horizontal components was considered, while for the GMPE provided by Kayen and Mitchell (1997) the sum of the two values of the horizontal components was used. Most of the points representing the ITACA +ESM_2017 database lie between the area enclosed by the attenuation curves in this case too: 119 out of 144 (about 83\%) values of Arias intensity plot between the curves when comparing with the GMPE by Sabetta and Pugliese (1996), especially for epicentral distances $R_{\mathrm{ep}}>4 \mathrm{~km}$ (Fig. 5a). A bit worse agreement is obtained with the relationship by Kayen and Mitchell (1997) (Fig. 5b), as 23 points out of $107(\approx 21 \%)$ plot below the range detected by the attenuation laws.

The computed values of mean period $T_{\mathrm{m}}$ and significant duration $D_{5-95}$ are compared in Fig. 6 with the GMPEs proposed by Rathje et al. (2004) and Kempton and Stewart (2006), for magnitudes $M=6-6.5$. These relationships were developed for the rock-like subsoil class only. The comparison is also made with the GMPEs provided by Tropeano et 

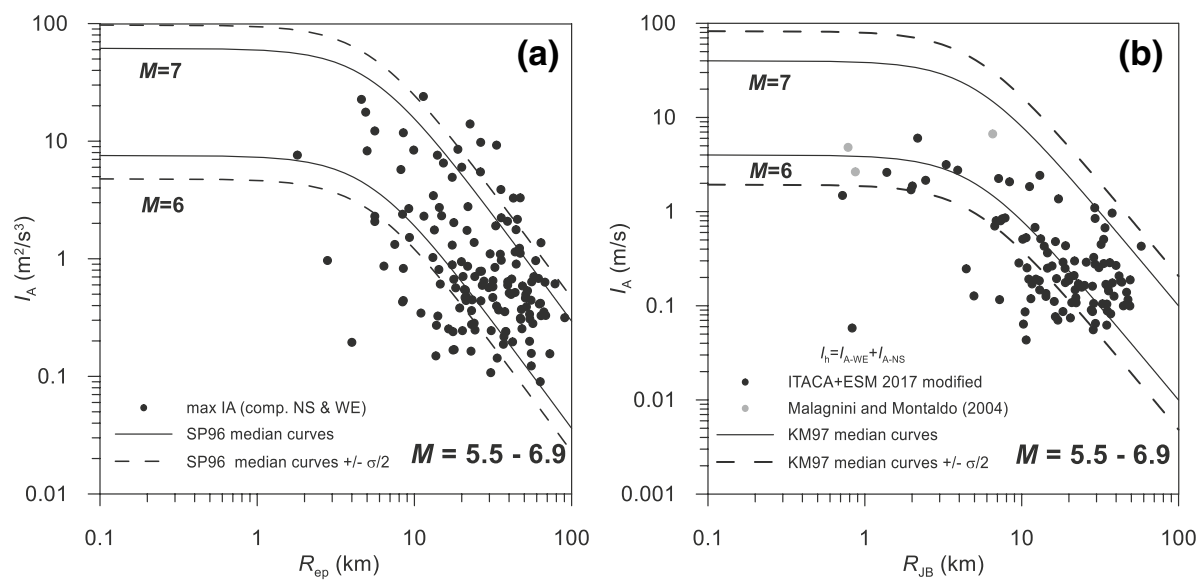

Fig. 5 Comparison between the Arias intensities recorded on stiff soils (ITACA +ESM_2017 database) and those computed using the GMPEs proposed by: a Sabetta and Pugliese (1996) and b Kayen and Mitchell (1997)
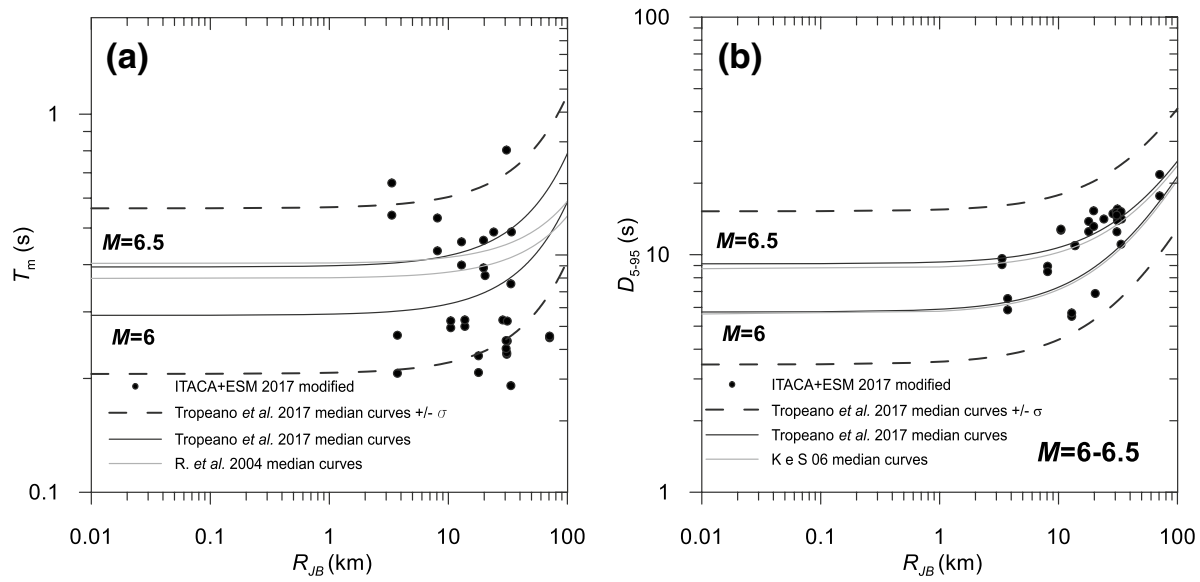

Fig. 6 Comparison between $\mathbf{a}$ the mean periods and $\mathbf{b}$ the significant durations recorded on rock-like soils, (ITACA + ESM_2017 database) and those computed using the GMPEs proposed by: a Rathje et al. (2004) and Tropeano et al. (2017); b Kempton and Stewart (2006) and Tropeano et al. (2017)

al. (2017) that reworked these relationships using the Italian database SISMA 2008. Figure $6 \mathrm{a}$ shows that 8 out of 31 points (about 26\%) representing the mean period $T_{\mathrm{m}}$ of the $I T A C A+E S M \_2017$ database fall just out of the range detected by the median $\pm \sigma$ curves provided by Tropeano et al. (2017). On the contrary, the values of significant duration $D_{5-95}$ obtained from the records agree with all the median curves proposed by the mentioned Authors, also capturing the increase of the significant duration with the Joyner and Boor distance.

To consider records significant for triggering sliding phenomena, a screening criterion of seismic records was introduced to predict permanent displacements with the 
rigid sliding-block model (Newmark 1965). According to Keefer and Wilson (1989), seismic events to be excluded from the database are those recorded at a source-to-site distance above the upper-bound curve shown in Fig. 7. The ITACA +ESM_2017 database includes 5 magnitude-distance pairs plotting slightly above this upper-bound curve, corresponding to 7 horizontal acceleration time histories ( 2 for subsoil class A, 1 for class B and 4 for group C, D, E). However, these time histories were not excluded in the end, as this would not involve significant changes in the results of the sliding-block analyses shown in the following.

\section{Evaluation of seismic-induced permanent displacements}

Permanent displacements induced by seismic actions were evaluated through a parametric integration of the acceleration time histories included in the database described in Sect. 2, i.e. by computing the seismic-induced permanent displacements through a double-integration of the equation of relative motion, as discussed below, for different values of some parameters characterising the seismic input (e.g. $P G A$ ) and the seismic resistance of the slope (e.g. the yield seismic coefficient $k_{\mathrm{y}}$ ). To this end, the rigid-block model sliding on a horizontal plane (Newmark 1965) was adopted (Fig. 8) both accounting for and ignoring the vertical component of ground motion. If the time history of the vertical seismic coefficient, $k_{\mathrm{v}}(t)$, is considered, the slope resistance to earthquake loading, represented by the yield seismic coefficient, $k_{\mathrm{y}}$, is not constant during the analysis as it becomes a function of time (Fig. 9). In this study, a simple though useful relationship to evaluate the yield seismic coefficient $k_{\mathrm{y}}(t)$ in the presence of $k_{\mathrm{v}}(t)$ is adopted following the formulation proposed by Sarma and Scorer (2009):

$$
k_{\mathrm{y}}(t)=\left[1-k_{\mathrm{v}}(t)\right] \cdot k_{\mathrm{y}\left(k_{\mathrm{v}}=0\right)}
$$

where $k_{\mathrm{y}\left(k_{\mathrm{v}}=0\right)}$ is the seismic yield coefficient computed in the absence of the vertical component. Equation (3) indicates that the yield coefficient $k_{\mathrm{y}}$, evaluated considering the vertical component of ground motion, can be either higher or lower than $k_{\mathrm{y}\left(k_{\mathrm{v}}=0\right)}$, depending on

Fig. 7 Screening of significant seismic events for slopes

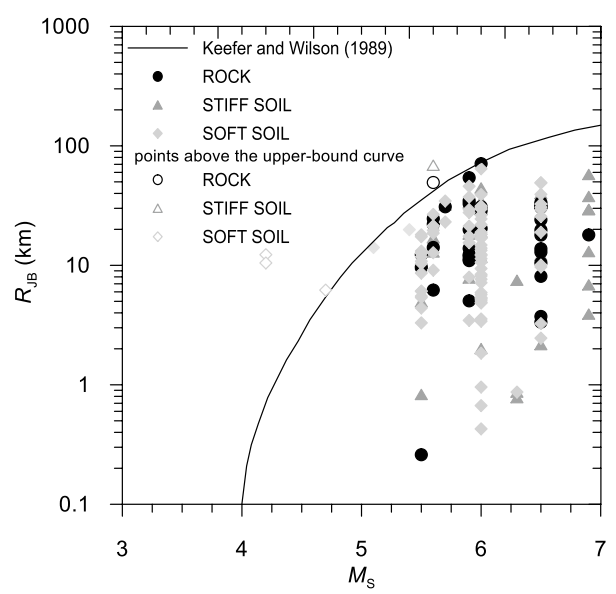


Fig. 8 Scheme of rigid slidingblock model ( adapted from Rathje et al. 2014)

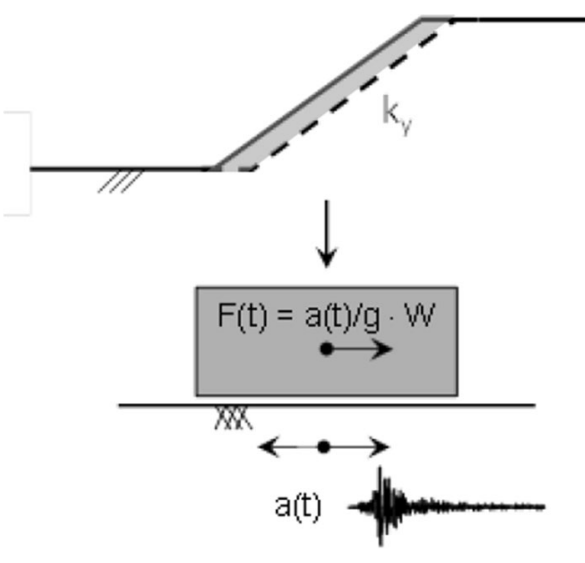

Fig. 9 Time histories of horizontal and yield accelerations

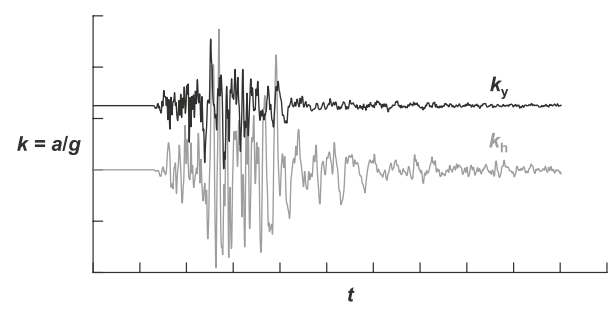

the sign assumed by $k_{\mathrm{v}}(t): k_{\mathrm{v}}>0$ is directed opposite to gravity, then reducing the available seismic resistance.

Permanent displacements were evaluated via double integration of the equation of relative motion of the rigid block, that can be written as (Michalowski and You 2000)

$$
d(t)=C \cdot \int_{0}^{T_{f}}\left\{\int_{0}^{T_{f}}\left[k_{\mathrm{h}}(t)-k_{\mathrm{y}}(t)\right] \cdot g \cdot d t\right\} \cdot d t
$$

where $k_{\mathrm{h}}(t)$ is the time history of the horizontal seismic coefficient, $g=9.81 \mathrm{~m} / \mathrm{s}^{2}$ is the gravitational acceleration, $T_{\mathrm{f}}$ is the duration of the seismic input and $C$ is a shape factor that accounts for the shape of the sliding surface. Referring to the simple scheme of infinite slope, the permanent displacement accumulated in the direction of the planar sliding surface can be evaluated using the following expression for the shape factor $C$ (Crespellani et al. 1998):

$$
C=\frac{\cos \left(\varphi^{\prime}-\beta\right)}{\cos \left(\varphi^{\prime}\right)}
$$

where $\varphi^{\prime}$ is the angle of shearing resistance and $\beta$ is the angle of slope inclination with respect to the horizontal. It is worth mentioning that Eq. (5) holds also to soils with effective cohesion $c^{\prime} \neq 0$. Typical and stable configurations are related to values of $\varphi^{\prime}$ and $\beta$ in the range $22^{\circ}-28^{\circ}$ and $5^{\circ}-20^{\circ}$, respectively, thus providing values of the shape factor $C$ ranging between 1.03 and 1.12 , close to unity. Hence, in calculation of permanent displacement a shape factor $C=1$ was assumed without loss in generality. 
Integration was carried out in the time intervals where the horizontal seismic coefficient, $k_{\mathrm{h}}(t)$, is greater than the yield seismic coefficient, $k_{\mathrm{y}}(t)$ (Fig. 9), and in all time instants when the relative velocity of the sliding block is positive. A null relative velocity was obtained at the end of the integration procedure by adding a set of $n$ zeros to the original time history of horizontal seismic coefficient, $k_{\mathrm{h}}(t), n$ being the initial number of points of $k_{\mathrm{h}}(t)$, this not affecting any ground motion parameter characterising the seismic input, such as its amplitude, frequency content or strong motion duration.

The parametric integration was carried out considering both signs of the acceleration time histories, assuming the maximum computed displacement as the slope displacement related to that seismic input. Influence of the vertical component of ground motion was observed to be negligible on the semi-empirical models developed in the following.

\section{Semi-empirical models for predicting slope displacements}

\subsection{One and two-ground motion parameters models}

Permanent displacements of slopes obtained through Newmark-type computations are first expressed as a function of ground motion parameters for a given value of the yield seismic coefficient. Following Rathje and Cho (2019), one or two ground motion parameters (GM) are used to derive the following expressions:

$$
\begin{gathered}
\ln (d)=A_{0}+A_{1} \cdot \ln \left(G M_{1}\right) \pm \sigma \cdot t \\
\ln (d)=A_{0}+A_{1} \cdot \ln \left(G M_{1}\right)+A_{2} \cdot \ln \left(G M_{2}\right) \pm \sigma \cdot t
\end{gathered}
$$

where $d$ is the displacement in units of $\mathrm{cm}, A_{0}, A_{1}$ and $A_{2}$ are regression coefficients, $G M_{1}$ and $G M_{2}$ are the ground motion parameters, $\sigma$ is the standard deviation of the model and $t$ is the reciprocal value of the normal standard distribution related to a generic level of confidence ( $t=0$ for median curves, here adopted). Displacements computed in these semiempirical relationships are obtained ignoring the vertical component of seismic motion; moreover, only displacements greater than $1 \mathrm{~cm}$ are taken into account to derive the regression coefficients, thus limiting the number of records used to 120, that is similar to the number of records considered by Rathje and Cho (2019) (105). Although the permanent displacements and the computed equations are sensitive to the assumed yield seismic coefficient $k_{\mathrm{y}}$, for the sake of comparison, the same value $k_{\mathrm{y}}=0.12$ as that adopted by Rathje and Cho (2019) is here assumed for the yield seismic coefficient in the integration of the Italian seismic database.

Computed displacements are plotted in Fig. 10 as a function of five ground motion parameters $\left(P G A, P G V, I_{\mathrm{A}}, T_{\mathrm{m}}\right.$ and $\mathrm{Sa}\left(1.5 T_{\mathrm{s}}\right)$ ), together with the relevant best-fit curves and the values of the standard deviation $\sigma$. Table 2 lists the regression parameters, together with the standard deviation of the model $\sigma$ and the coefficient of determination $R^{2}$. Increasing permanent displacements $d$ are obtained for increasing values of all the considered seismic parameters. Among the one-parameter models, the smallest standard deviation $(\sigma=0.535)$ is obtained using $I_{\mathrm{A}}$, that describes intensity, frequency content and duration of the ground motion, thus resulting the most efficient parameter. The standard deviation of $P G V$ model $(\sigma=0.581)$ is slightly larger than the one computed using the Arias intensity. However, the $P G V$ model may result in a simpler use in that $P G V$ can be evaluated using one of 


$$
k_{\mathrm{y}}=0.12
$$
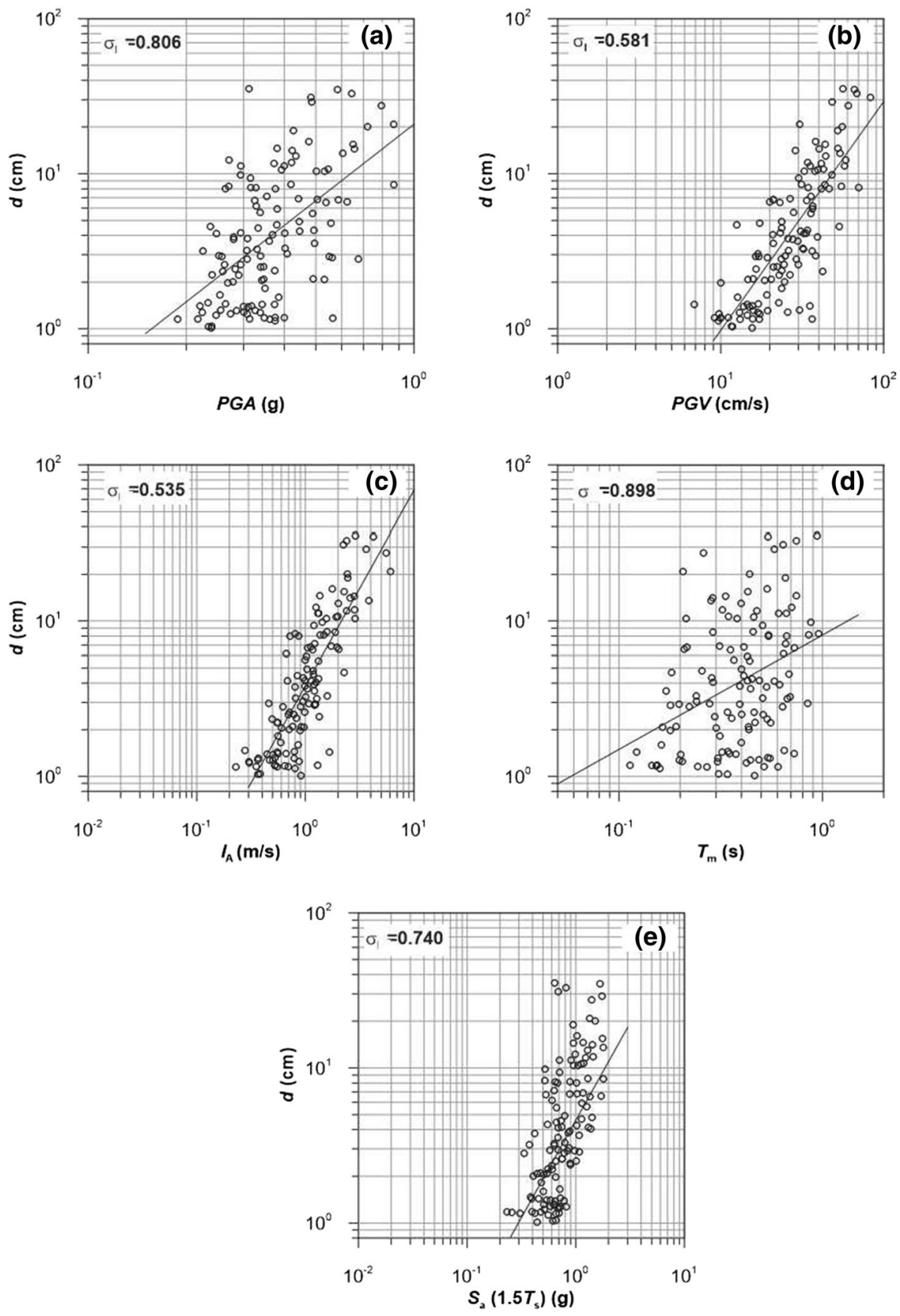

Fig. 10 Single Ground Motion Parameter semi-empirical relationships, where permanent displacement is expressed against: a peak ground acceleration, b peak ground velocity, c Arias intensity, $\mathbf{d}$ mean period, and $\mathbf{e}$ spectral acceleration at $1.5 T_{\mathrm{s}}(120$ records $)$ 
Table 2 Regression parameters for displacement models using different ground motion parameters and $k_{\mathrm{y}}=0.12(d>1 \mathrm{~cm})$ : in brackets the results obtained by Rathje and Cho (2019)

\begin{tabular}{lclllll}
\hline $\begin{array}{l}\text { Ground motion } \\
\text { parameter }\end{array}$ & \multicolumn{1}{l}{$A_{0}(\mathrm{~cm})$} & $A_{1}$ & $A_{2}$ & $A_{1} / A_{2}$ & $\sigma(\mathrm{cm})$ & $R^{2}$ \\
\hline$P G A(\mathrm{~g})$ & $3.037(4.14)$ & $1.638(1.16)$ & - & - & $0.806(0.636)$ & 0.305 \\
$P G V(\mathrm{~cm} / \mathrm{s})$ & $-3.421(-1.09)$ & $1.476(1.16)$ & - & - & $0.581(0.483)$ & 0.638 \\
$I_{\mathrm{A}}(\mathrm{m} / \mathrm{s})$ & $1.346(2.83)$ & $1.253(0.78)$ & - & - & $0.535(0.420)$ & 0.694 \\
$T_{\mathrm{m}}(\mathrm{s})$ & $2.096(2.67)$ & $0.736(0.53)$ & - & - & $0.898(1.149)$ & 0.414 \\
$S_{\mathrm{a}}\left(1.5 \mathrm{~T}_{\mathrm{s}}\right)(\mathrm{g})$ & $1.791(3.31)$ & $1.446(1.15)$ & - & - & $0.740(0.683)$ & 0.137 \\
$P G A(\mathrm{~g}), P G V$ & $-1.710(0.72)$ & $1.196(0.50)$ & $1.320(0.82)$ & $0.91(0.61)$ & $0.441(0.391)$ & 0.794 \\
$\quad(\mathrm{~cm} / \mathrm{s})$ & & & & & & \\
$P G A(\mathrm{~g}), T_{\mathrm{m}}(\mathrm{s})$ & $5.139(5.05)$ & $2.421(1.29)$ & $1.360(0.97)$ & $1.78(1.33)$ & $0.528(0.396)$ & 0.704 \\
$P G A(\mathrm{~g}), I_{\mathrm{A}}(\mathrm{m} / \mathrm{s})$ & $1.461(2.36)$ & $0.113(-0.39)$ & $0.216(1.01)$ & $0.52(-0.39)$ & $0.536(0.403)$ & 0.695 \\
$I_{\mathrm{A}}(\mathrm{m} / \mathrm{s}), P G V$ & $-1.637(1.02)$ & $0.857(0.48)$ & $0.919(0.55)$ & $0.93(0.87)$ & $0.347(0.314)$ & 0.872 \\
$(\mathrm{~cm} / \mathrm{s})$ & & & & & & \\
$I_{\mathrm{A}}(\mathrm{m} / \mathrm{s}), T_{\mathrm{m}}(\mathrm{s})$ & $2.047(3.25)$ & $1.250(0.79)$ & $0.726(0.56)$ & $1.72(1.41)$ & $0.403(0.298)$ & 0.827 \\
\hline
\end{tabular}

the several Ground Motion Prediction Equations (GMPEs) available in the literature. Moreover, GMPEs developed for Arias intensity $I_{\mathrm{A}}$ may be affected by a higher epistemic uncertainty than that of GMPEs built for $P G A$ or $P G V$, this resulting in a higher standard deviation of the model (Campbell and Bozorgnia 2012; Douglas 2012). The standard deviation related to $P G A, S \mathrm{a}\left(1.5 T_{\mathrm{s}}\right)$ and $T_{\mathrm{m}}$ models is larger than 0.7: this is because $P G A$ and $\mathrm{Sa}\left(1.5 T_{\mathrm{s}}\right)$ do not account for the frequency content of ground motion, while the mean period $T_{\mathrm{m}}$ does not consider its intensity.

Considering the two ground motion parameter models, the lowest values of standard deviation are computed when considering the $I_{\mathrm{A}}-T_{\mathrm{m}}$ and the $I_{\mathrm{A}}-P G V$ models, with values of $\sigma=0.403$ and 0.347 , respectively. The standard deviation related to other pairs of parameters $\left(P G A-P G V ; P G A-T_{\mathrm{m}}\right.$; and $\left.P G A-I_{\mathrm{A}}\right)$ are about equal to 0.5 , similar to the value obtained for the single parameter $I_{\mathrm{A}}$ model $(\sigma=0.535)$. The smaller standard deviation computed using the couples $I_{\mathrm{A}}-T_{\mathrm{m}}$ and $I_{\mathrm{A}}-P G V$ results from the information on the frequency content provided by either $T_{\mathrm{m}}$ or $P G V$. Similar values of $\sigma$ computed for the two parameters ( $P G A$, $\left.I_{\mathrm{A}}\right)$ and one parameter $\left(I_{\mathrm{A}}\right)$ models suggest that information about intensity provided by $P G A$ is already represented by $I_{\mathrm{A}}$ so that data scattering is not reduced by adding $P G A$.

Based on the computed standard deviation, the best one-parameter model is the $I_{\mathrm{A}}$ model with a value of $\sigma$ similar to those computed for most of the two-parameter models. The best two-parameter models are the $I_{\mathrm{A}}-T_{\mathrm{m}}$ and $I_{\mathrm{A}}-P G V$ models, characterised by values of $\sigma$ about $25 \%$ and $35 \%$ smaller than that of the $I_{\mathrm{A}}$ model. However, the main issue in using these three models consists in the lack of hazard maps for expected, site-specific values of $I_{\mathrm{A}}$ and $T_{\mathrm{m}}$. Therefore, the $P G A-P G V$ model may be preferred to the previous ones due to the fact that several ground motion models are available for $P G A$ and $P G V$ (e.g. Rathje and Cho 2019).

Regression parameters and standard deviations computed by Rathje and Cho (2019) are also listed in Table 2: the intercepts $A_{0}$ are always larger than those obtained in this study, due to the larger computed permanent displacements, except for what obtained in the $P G A$, $T_{\mathrm{m}}$ model. This result can be attributed to the different adopted seismic database that is characterised by much higher earthquake magnitudes $\left(M_{\mathrm{w}}>6.5\right)$. Values of parameter $A_{1}$ obtained in this study are 26 to $61 \%$ higher than those computed by Rathje and Cho (2019) 
for one-ground motion parameter models. Similarly, higher values of $A_{2}$ are evaluated in the two-GM parameter relationships ( $+67 \%$ at most), except for the $P G A, I_{\mathrm{A}}$ equation $(-70 \%)$. A fair agreement is obtained in terms of the standard deviation $\sigma$ of the models, this being either higher or lower than those by Rathje and Cho (2019) of about the same amount (maximum difference of about $\pm 35 \%$ ).

The semi-empirical relationships showed in this paragraph relate permanent displacements to some ground motion parameters, for a given yield coefficient of the slope $k_{\mathrm{y}}$; different semi-empirical models can be obtained specifying different values of $k_{\mathrm{y}}$, thus referring to slopes characterised by different seismic resistances. These curves can then be used as a tool to develop site-specific displacement hazard curves within a fully-probabilistic approach. By contrast, semi-empirical curves proposed in the following paragraphs (Sects. 4.2 and 4.3) are meant to be adopted either to calibrate the seismic coefficient $k$ or to estimate the maximum expected permanent displacement $d$, in the framework of a deterministic approach.

\subsection{Evaluation of the seismic coefficient}

Empirical relationships to evaluate earthquake-induced displacements can be extended introducing the yield seismic coefficient $k_{\mathrm{y}}$ as an added independent variable. Permanent displacements can then be computed for slope-specific values of $k_{\mathrm{y}}$ and compared with threshold values related to the level of seismic performance desired for the slope at hand. However, the pseudo-static approach is still the most common procedure adopted to evaluate the seismic stability of a slope, thanks to its simplicity and to the experience accumulated by engineers in using this approach in the framework of the limit-equilibrium force-based computations. In a pseudo-static analysis, inertial actions are represented by static-equivalent forces proportional to the self-weight of the unstable mass through the seismic coefficient $k$, whose selection is crucial. The pseudo-static approach provides an evaluation of a safety factor against sliding that is assimilated to a failure mechanism. Nevertheless, as mentioned above, the inertial effects mainly produce a progressive development of permanent displacements in the slope rather than a failure mechanism, due to the transient and cyclic nature of seismic actions. Using the pseudo-static approach for the evaluation of slope stability under seismic conditions then requires relating the maximum expected displacements to the seismic coefficient $k$ and the safety factor $F_{\mathrm{S}}$. Such an equivalence can be obtained using relationships of the kind mentioned above between earthquake-induced displacements and given ground motion parameters. Specifically, upperbound relationships relating earthquake-induced displacements to the ratio $k_{\mathrm{y}} / k_{\max }$ can be used, following Rampello et al. (2010). For each subsoil class and acceleration level, an exponential relationship between the permanent displacement $d$ and the ratio $k_{\mathrm{y}} / k_{\max }$ can be written in the form:

$$
d=B \cdot e^{-A \frac{k_{\mathrm{y}}}{k_{\max }}}
$$

where $A$ is a non-dimensional coefficient defining the slope of the curve in a semi-logarithmic scale and $B$ is the displacement for $k_{\mathrm{y}}=0$. Assuming a log-normal distribution for displacements, the median curve corresponding to the 50th percentile is obtained (coefficients $A$ and $B$ ), as well as the upper-bound curve corresponding to the 94th percentile, (coefficients $A$ and $B_{1}>B$ ), which is a value in the range of those commonly adopted in the literature (e.g. Whitman and Liao 1985; Rampello et al. 2010; Biondi et al. 2014). The 
slope $A$ computed for the median curve was also used for the upper-bound curve $\left(A_{1}=A\right)$, thus assuming a constant standard deviation irrespective of the ratio $k_{\mathrm{y}} / k_{\max }$. This hypothesis was validated by performing preliminary analyses in which negligible differences were obtained considering the dependence of $\sigma$ on the ratio $k_{\mathrm{y}} / k_{\max }$.

In deriving these upper-bound relationships, incompleteness of data used for the parametric integration should be considered, in that the available acceleration time histories were recorded during the last 40-50 years, a very short period if compared to the return periods typically considered when checking the safety of slopes subjected to seismic events. Therefore, the horizontal acceleration time histories included in the database $I T A C A+E S M \_2017$ were scaled to reach desired values of $P G A$ equal to $0.05,0.15,0.25$ and $0.35 \mathrm{~g}$, following the Italian Building Code (Ministero delle Infrastrutture 2018), limiting the scale factor $F_{\mathrm{h}}$ in the range $0.5-2$. Such a narrow interval for $F_{\mathrm{h}}$ allowed to preserve site effects; moreover, the frequency content and the strong-motion duration of the records were not affected by the scaling operation. The same scaling factor $\left(F_{\mathrm{h}}=F_{\mathrm{v}}\right)$ was adopted for the time histories of vertical acceleration. In the presence of both horizontal components (NS and WE), the vertical accelerograms were scaled twice, according to the scale factors $F_{\mathrm{h}}$ used in each horizontal direction. Therefore, four different sets of acceleration time histories were obtained for each subsoil group (rock-like, stiff and soft soils).

Calculations of permanent displacements were carried out using the four sets of scaled time histories varying the yield seismic coefficient $k_{\mathrm{y}\left(k_{\mathrm{v}}=0\right)}$ from 10 to $80 \%$ of the maximum seismic coefficient $k_{\max }\left(k_{\mathrm{y}} / k_{\max }=0.1-0.8\right)$.

\subsubsection{Influence of the vertical component of ground motion}

Seismic-induced permanent displacements were computed both in the presence and in the absence of the vertical component of ground motion, fitting the results with the upperbound curves given in Eq. (8). The computed upper-bound curves for soft soils (subsoil classes C, D, E) are shown in Fig. 11: for low to intermediate levels of peak acceleration, the curves obtained considering the vertical component provide slightly greater displacements, while for $P G A=0.35 \mathrm{~g}$, upper-bound curves overlap. The observed differences are less than $10 \%$ so that they can be ignored, leading to the conclusion that the vertical component of ground motion does not affect substantially the upper-bound curves and thus the

Fig. 11 Comparison between the upper-bound curves (94th percentile) calculated in the presence and absence of the vertical component of ground motion for soft soils

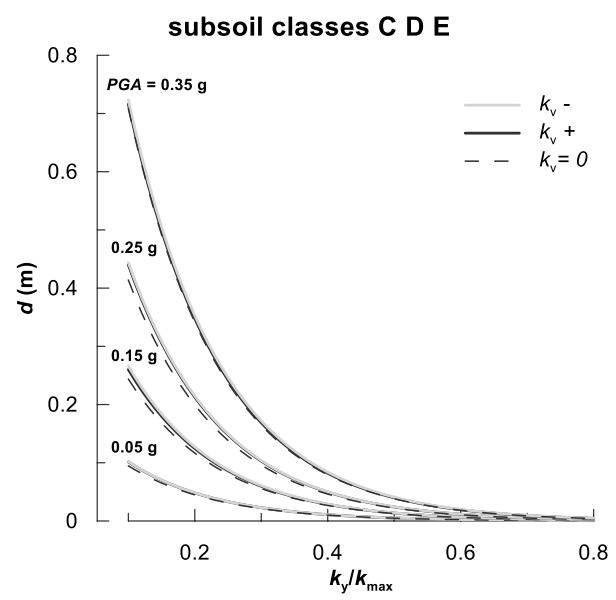


choice of the seismic coefficient adopted in a pseudo-static analysis. Similar results were obtained for the other subsoil classes considered in this study (A and B). The same conclusion was drawn in some studies adopting different seismic inputs (Gazetas et al. 2009; Sarma and Scorer 2009). Then, the time histories of horizontal acceleration only are used in the computation presented in the following.

\subsubsection{Upper-bound empirical curves}

Seismic-induced permanent displacements are plotted in Fig. 12 as a function of the ratio $k_{\mathrm{y}} / k_{\max }$ between the yield and the maximum seismic coefficients for the subsoil class $\mathrm{B}$ (stiff soils) only. The median (50th percentile, dashed lines) and the upper-bound curves (94th percentile, solid lines) are plotted in the figure, for each acceleration level. As expected, seismic-induced displacements decrease as the ratio $k_{\mathrm{y}} / k_{\max }$ increases and the peak acceleration $P G A$ decreases, this occurring for all subsoil groups.

subsoil class $B$
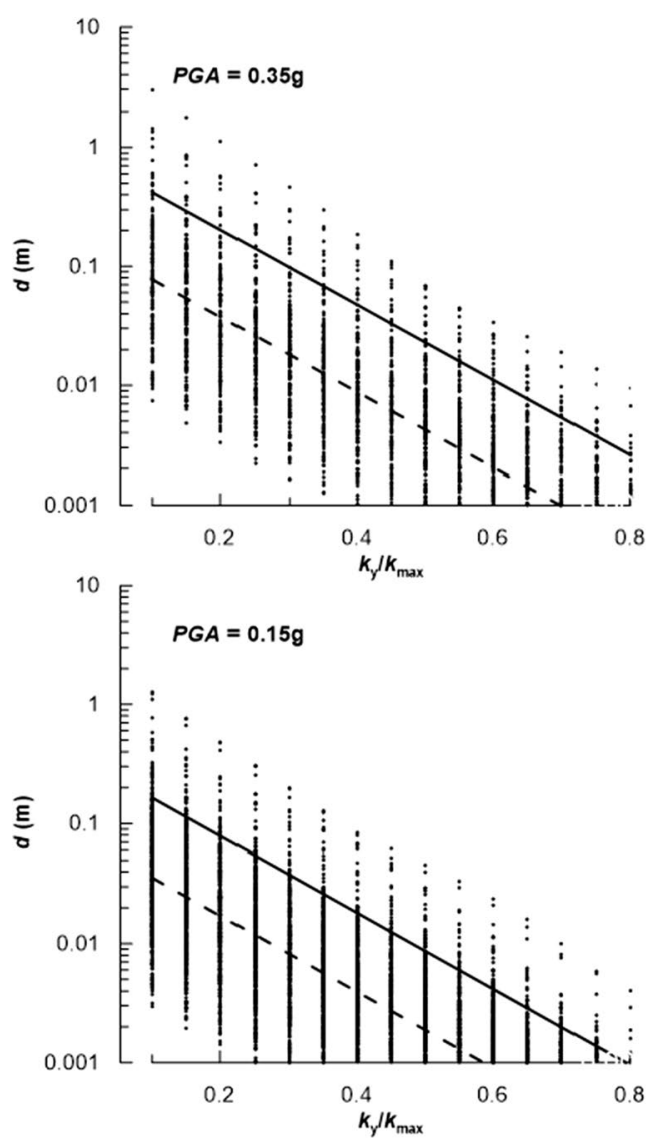

- - - median curve (50th percentile)

upper-bound curve (94th percentile)
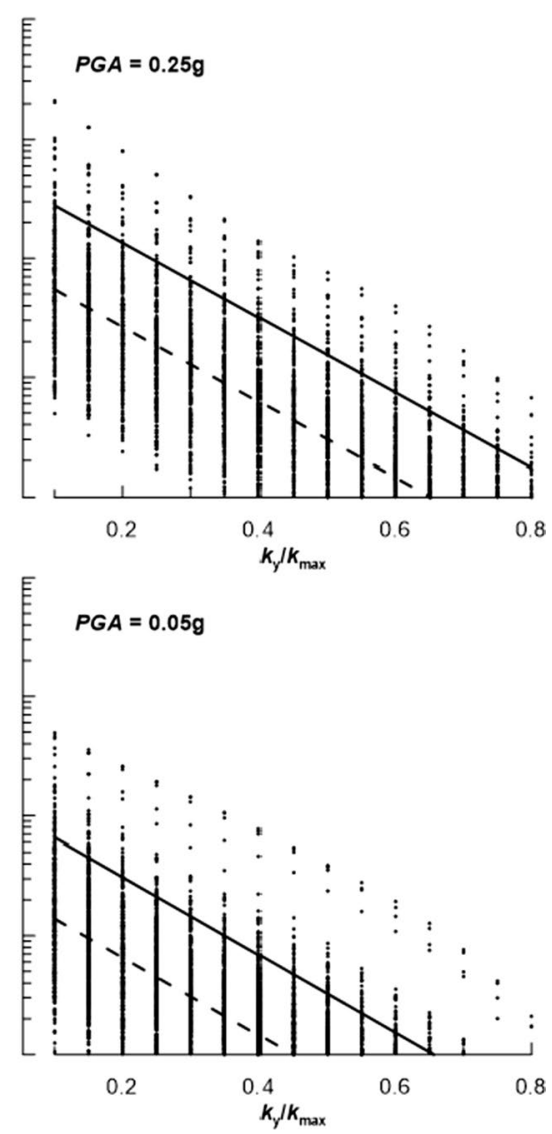

Fig. 12 Permanent displacements computed using acceleration time histories recorded on stiff subsoils 
The upper-bound curves computed for the three subsoil groups are compared in Fig. 13. The maximum permanent displacements are invariably computed for soft subsoils: this result is not surprising and is to be attributed, for a fixed value of the peak ground acceleration $P G A$, to the typical frequency content and significant duration characterising the acceleration time histories recorded on this type of soils. Indeed, propagation of seismic waves through them causes both the mean period $T_{\mathrm{m}}$ and the significant duration $D_{5-95}$ increase (see Fig. 2), this leading to a strong increase of the permanent displacement accumulated till the end of the seismic event. In contrast, the lowest displacements are calculated for the stiff or rock-like subsoils, depending on the peak ground acceleration $P G A$ and $k_{\mathrm{y}} / k_{\max }$ ratio. Specifically, for low acceleration levels $(P G A=0.15$ and $0.05 \mathrm{~g})$ the lowest displacements are obtained for the subsoil class A, while for high accelerations $(P G A=0.35 \mathrm{~g})$ they are attained for stiff soils (subsoil class B). This result might appear counterintuitive, as local (i.e. stratigraphic) effects are supposed to produce upper-bound relationships for subsoil class B plotting above the one obtained for subsoil class A. However, the largely different sample size for the two subsoil classes A and B, equal to 390 and 2490 respectively,
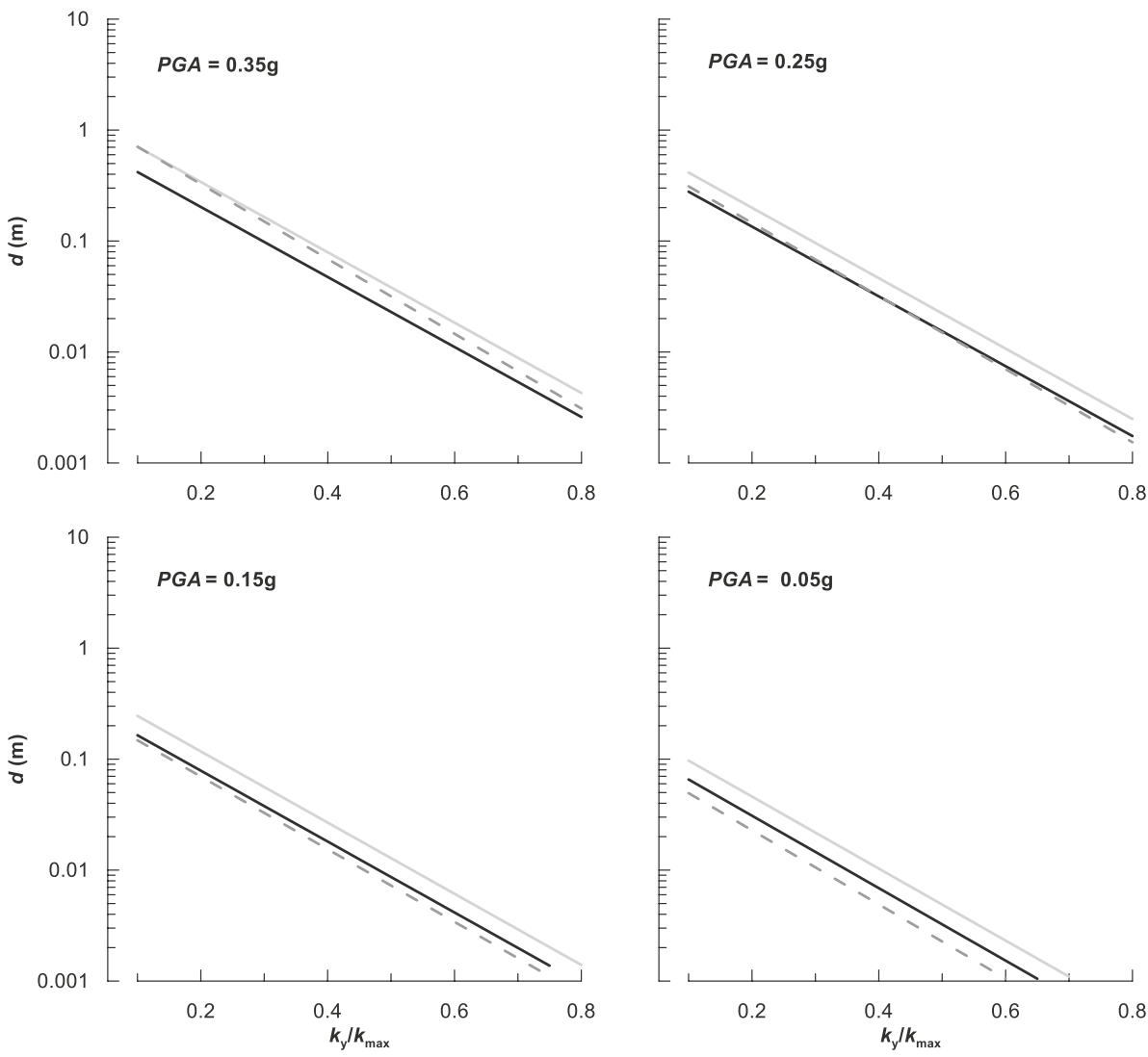

Fig. 13 Comparison amongst upper-bound permanent displacements obtained for the different subsoil groups 
caused a higher coefficient of variation $\gamma_{\ln }=\sigma_{\ln } / \mu_{\ln }$ for the subsoil class A, and therefore a greater shift from the median to the upper-bound curve. Conversely, for $P G A=0.25 \mathrm{~g}$, negligible differences are observed between subsoil classes A and B. It is worth mentioning that the adequateness of the sample size $n$ has been checked for all subsoil classes and acceleration levels by verifying that the residuals of $\ln (d), \varepsilon_{\mathrm{ln}}$, follow a normal distribution in all considered cases.

Values of coefficient $A$ are in the range of 7.24-7.76 with a mean value equal to 7.45, while $B_{1}$ ranges between 0.11 and $1.54 \mathrm{~m}$, with an average of $0.63 \mathrm{~m}$ and a coefficient of variation of about $76 \%$ (Table 3 ). These values are compared with those computed by Rampello et al. (2010) using the database SISMA (Scasserra et al. 2008): while the slope $A$ is quite similar, with a maximum difference of $8 \%$, coefficient $B_{1}$ computed with database $I T A C A+E S M \_2017$ always attains lower values, up to $-72 \%$, except for the soft subsoils at high peak ground accelerations $P G A(=0.35$ and $0.25 \mathrm{~g})$, for which an almost double value is obtained. This outcome resulted in lower permanent displacements except for the soft subsoils at high $P G A$. The observed differences come from the different databases adopted in calculations, as many changes occurred over the years in the attribution of subsoil classes to the recording stations (Felicetta et al. 2017); moreover, the database used by Rampello et al. (2010) is updated to 2002, while that adopted in this study is updated to 2017. Table 3 also lists the values of the standard deviation of the model $\sigma$ and of the coefficient of determination $R^{2}$ : a quite narrow range of values is detected, with $\sigma=0.91-1.15$ and $R^{2}=0.66-0.77$.

Computation of coefficients $A$ and $B_{1}$ was repeated adopting horizontal acceleration time histories recorded by stations not affected by any local effects, thus obtaining a smaller set of accelerograms. To this end, the descriptive data of the recording site available in the database ITACA +ESM_2017, together with its topographical and morphological conditions, were selected. Specifically, free-field housing and plain, centre of Valley and not classified morphological conditions were chosen, thus reducing the number of considered stations from 297 to 115 . Table 4 shows the coefficients $A$ and $B_{1}$ obtained using the reduced database. Slight variations in the coefficient $A$ were computed, with a maximum difference of about $7 \%$ obtained for rock-like subsoils and $P G A=0.35 \mathrm{~g}$, while changes in the coefficient $B_{1}$ were at most equal to about $35 \%$ for soft subsoils and $P G A=0.05 \mathrm{~g}$. Similar results were obtained for standard deviation of the model $\sigma$ and the coefficient of determination $R^{2}$, the former ranging between 0.92 and 1.28 , the latter between 0.60 and 0.78 , similarly to what obtained with the complete database. Upper-bound relationships from the complete database are then considered in the following, due to the small differences.

\subsubsection{Seismic coefficient}

Assuming a ductile behaviour along the sliding surface, thus assuming a constant shear strength, the seismic coefficient $k$ can be estimated as a fraction of the maximum seismic coefficient $k_{\max }$ by applying the position $k=\eta \cdot k_{\max }$ with $\eta \leq 1$. Specifically, $k$ can be related to the desired upper-bound threshold displacement $d_{\mathrm{y}}$ inverting Eq. (8) as follows (Fig. 14):

$$
k=\eta \cdot k_{\max }=\left[-\frac{\ln \left(d_{\mathrm{y}} / B_{1}\right)}{A}\right] \cdot k_{\max }
$$

where coefficient $B_{1}$ corresponds to the upper-bound curves (94th percentile) presented in the previous paragraph for different acceleration levels, to introduce a fixed level of 

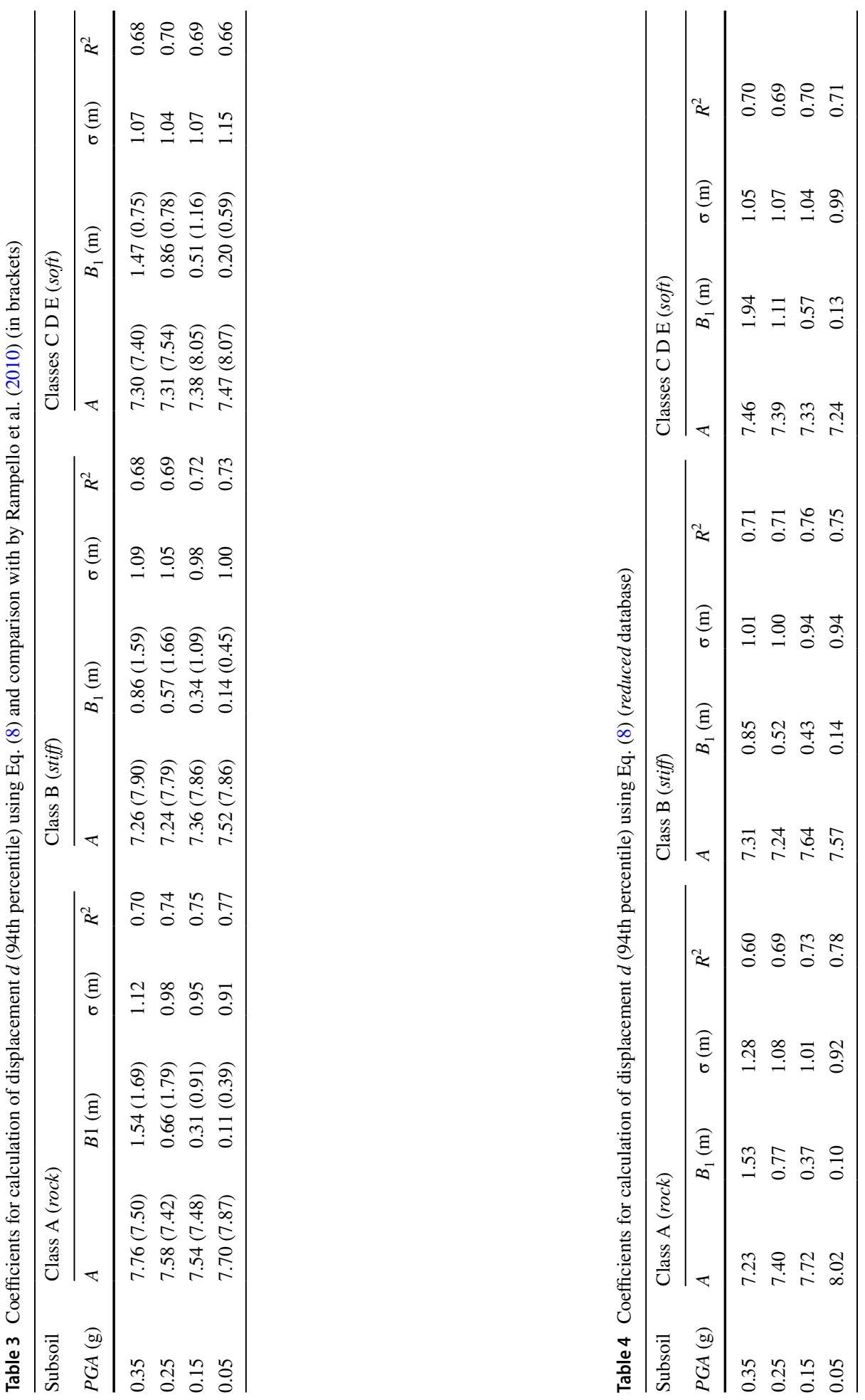
Fig. 14 Equivalence between upper-bound permanent displacements and seismic coefficient
Table 5 Values of coefficient $\eta$ for given threshold displacements

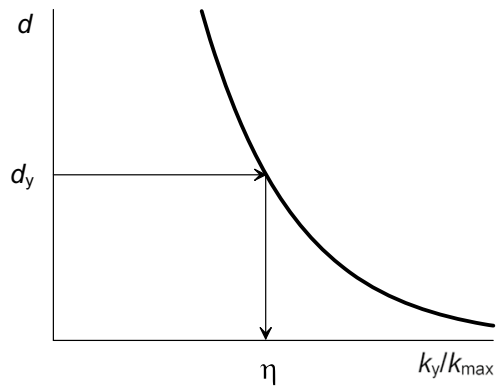

\begin{tabular}{|c|c|c|c|c|c|c|c|c|c|}
\hline $\begin{array}{l}d_{\mathrm{y}}(\mathrm{m}) \\
P G A(\mathrm{~g})\end{array}$ & $\begin{array}{l}0.15 \\
\eta \text { (cla }\end{array}$ & $\begin{array}{r}0.05 \\
\text { ss A) }\end{array}$ & 0.02 & $\begin{array}{l}0.15 \\
\eta \text { (cla }\end{array}$ & $\begin{array}{r}0.05 \\
\text { ss B) }\end{array}$ & 0.02 & $\begin{array}{l}0.15 \\
\eta \text { (cla }\end{array}$ & $\begin{array}{c}0.05 \\
\text { sses C }\end{array}$ & $\begin{array}{c}0.02 \\
\text { D E) }\end{array}$ \\
\hline 0.35 & 0.30 & 0.44 & 0.56 & 0.24 & 0.39 & 0.52 & 0.31 & 0.46 & 0.59 \\
\hline 0.25 & 0.20 & 0.34 & 0.46 & 0.19 & 0.34 & 0.46 & 0.24 & 0.39 & 0.51 \\
\hline 0.15 & 0.10 & 0.24 & 0.37 & 0.11 & 0.26 & 0.39 & 0.17 & 0.32 & 0.44 \\
\hline 0.05 & 0.10 & 0.10 & 0.22 & 0.10 & 0.14 & 0.26 & 0.10 & 0.19 & 0.31 \\
\hline
\end{tabular}

conservativism in the estimation of $k$ (Stewart et al. 2003). Hence, if a pseudo-static analysis is performed and limit equilibrium is reached $\left(F_{\mathrm{S}}=1\right)$, it is $k=k_{\mathrm{y}}$, this corresponding to a maximum permanent displacement $d=d_{\mathrm{y}}$. This procedure constitutes the link between the force-based pseudo-static approach and the permanent displacements computed via the semi-empirical relationship as the one given in Eq. (9).

Computed values of coefficient $\eta$ are given in Table 5, for selected values of threshold displacements $d_{\mathrm{y}}$, equal to 15,5 and $2 \mathrm{~cm}$. Threshold values of 15 and $5 \mathrm{~cm}$ correspond to moderate to negligible levels of damage assuming a ductile slope behaviour during sliding, in the absence and presence of manufactures (Idriss, 1985), while $d_{\mathrm{y}}=2 \mathrm{~cm}$ was considered acceptable by Wilson and Keefer (1985) for stiff soils and rocks, characterised by a brittle behaviour. A minimum safe value of $\eta=0.10$ was assumed when calculations returned $\eta<0.10$. This occurred for high admissible permanent displacements $\left(d_{\mathrm{y}}=15 \mathrm{~cm}\right)$ and low acceleration levels $(P G A=0.05 \mathrm{~g})$.

It is worth noting that, since the deformation pattern of a slope may deeply differ from the simple sliding along a well-defined surface, as assumed in the analyses, threshold value of $d_{\mathrm{y}}$ should be solely considered as an index of seismic performance of the slope.

Different coefficients $\eta$ can be computed assuming different threshold displacements. The discussed procedure can also be adopted assuming other levels of conservativism, using different percentile to define the upper-bound curves reported in Eq. (8).

\subsection{Further semi-empirical relationships}

In the procedure discussed in Sect. 4.2, seismic-induced permanent displacements were related to the ratio between the yield and the maximum seismic coefficients, $k_{\mathrm{y}} / k_{\mathrm{max}}$, thus describing the seismic input by its amplitude only. The remarkable scattering of the data 
points shown in Fig. 12 reveals that permanent displacements do not only depend on the peak acceleration acting on the potential sliding mass, but on other parameters characterising the seismic motion as well. This led to the development of a number of semi-empirical relationships, where the ground motion is described by additional parameters such as the mean period $T_{\mathrm{m}}$, that reflects the frequency content of the seismic input, the significant duration $D_{5-95}$, that quantifies the duration of the strong-motion phase, and the Arias intensity $I_{\mathrm{A}}$, that represents the energy content of the seismic event.

\subsubsection{Seismic input described via $k_{\text {max }}, T_{\mathrm{m}}$ and $D_{5-95}$}

Empirical relationships are used herein where the permanent displacement $d$ (variable 1) or the normalised displacement $\bar{d}$ (variable 2) (Yegian et al. 1991):

$$
\bar{d}=\frac{d}{P G A \cdot T_{\mathrm{m}} \cdot D_{5-95}}
$$

is expressed as a function of peak acceleration $P G A$, mean period $T_{\mathrm{m}}$ and significant duration $D_{5-95}$, to account for the influence of frequency content and duration of ground motion (Madiai 2009; Biondi et al. 2011; Tropeano et al. 2017). Permanent displacement $d$ strongly depends on site conditions, while the normalised displacement $\bar{d}$ has the advantage to be almost site-independent thanks to the inclusion of 3 ground motion parameters ( $P G A, T_{\mathrm{m}}$ and $D_{5-95}$ ) explicitly accounting for the stratigraphic effects.

Following Biondi et al. (2011), three semi-empirical relationships can be obtained ( $a$, $b$ and $c$ ) and used for both variables $d$ and $\bar{d}$, thus providing six different equations: 1a, $1 \mathrm{~b}$ and $1 \mathrm{c}$ for permanent displacement $d$ and $2 \mathrm{a}, 2 \mathrm{~b}$ and $2 \mathrm{c}$ for the normalised displacement $\bar{d}$, namely:

$$
\begin{gathered}
\text { (a) } \log (d ; \bar{d})=A \cdot \frac{k_{y}}{k_{\max }}+B \pm \sigma \cdot t \\
\text { (b) } \log (d ; \bar{d})=A \cdot \log \left(1-\frac{k_{y}}{k_{\max }}\right)+B \cdot \log \left(\frac{k_{y}}{k_{\max }}\right)+C \pm \sigma \cdot t \\
\text { (c) } \log (d ; \bar{d})=A \cdot\left(\frac{k_{y}}{k_{\max }}\right)^{3}+B \cdot\left(\frac{k_{y}}{k_{\max }}\right)^{2}+C \cdot\left(\frac{k_{y}}{k_{\max }}\right)+D \pm \sigma \cdot t
\end{gathered}
$$

where $\sigma$ is the standard deviation of the considered functional form and $t$ is the abovementioned reciprocal value of the normal standard distribution ( $t=1.555$ for 94 th percentile, here adopted). Again, as in Sect. 4.2, a constant standard deviation $\sigma$ was assumed in computations. Relationship (a) (Eq. 11) is equivalent to the one presented in Eq. (8), while relationship (b) (Eq. 12) complies with the following conditions: $d \rightarrow \infty$ for $k_{\mathrm{y}} / k_{\max }=0$ and $d=0$ for $k_{\mathrm{y}} / k_{\max }=1$ (Ambraseys and Menu 1988). Relationship (c) (Eq. 13) was formulated following Saygili and Rathje (2008).

Coefficients $A, B, C$ and $D$ characterising the different regressions are given in the Appendix 2, together with the relevant values of the standard deviation $\sigma$ and the coefficient of determination $R^{2}$. Type 2 relationships provide a better best-estimate of analysis results with higher values of $R^{2}$, thanks to the dimensionless expression adopted for 
permanent displacements. The maximum increase of $R^{2}$ was computed for soft soils, with a maximum increase of about $22 \%$ for $P G A=0.05 \mathrm{~g}$.

The upper-bound curves computed using Eqs. (11)-(13) are plotted in Fig. 15. The results related to regressions $(a),(b)$ and $(c)$ are superimposed in the figures, for the permanent displacement $d(1)$ (Fig. 15a, c, e) and the non-dimensional displacement $\bar{d}(2)$ (Fig. 15b, d, f), for each subsoil class and two acceleration levels $(P G A=0.35$ and $0.15 \mathrm{~g})$. Regressions $(a)$ to $(c)$ provide very similar upper-bound displacements, for all subsoil groups and peak accelerations $P G A$, with the maximum difference of about $30 \%$ obtained for stiff soils at high accelerations $(P G A=0.35 \mathrm{~g})$ and for ratio $k_{\mathrm{y}} / k_{\max }=0.80$, the latter involving very low permanent displacements $d$ or $\bar{d}$. Influence of $P G A$ is mostly mitigated using the non-dimensional displacement $\bar{d}$, reducing sensibly the maximum difference between the permanent displacements computed for $P G A=0.35$ and $0.15 g$ (Fig. 15) from about 380 to $50 \%$, the latter value obtained for subsoil class B.

No significant improvement in the evaluation of permanent displacements is observed from $a$ to $c$ semi-empirical curves, so that relationship $2 a$ is advised due to its simple form. However, relationships of type 2 need an estimate of ground motion parameters $T_{\mathrm{m}}$ and $D_{5-95}$ : to this end, the GMPEs proposed in Sect. 2 as well as in the literature can be used, this requiring evaluation of magnitude $M$ and of epicentral or Joyner and Boore distance, $R_{\text {ep }}$ or $R_{\mathrm{JB}}$, respectively (Tropeano et al. 2017).

Influence of subsoil groups on permanent displacements is shown in Figs. 16 and 17, for relationships of types $l(d)$ and $2(\bar{d})$. Similarly to what observed by Biondi et al. (2011) and Tropeano et al. (2017), permanent displacements $d$ depend on subsoil group (Fig. 16), as also discussed in Sect. 4.2.2. The largest differences among subsoil groups in the evaluation of permanent displacement $d$ are obtained comparing stiff (class $\mathrm{B}$ ) and soft soils (classes C, D and E), the latter providing higher permanent displacements (about $+70 \%$ ) for $P G A=0.35 \mathrm{~g}$ and $k_{\mathrm{y}} / k_{\max }=0.45$. Conversely, Fig. 17 shows that the dependence of upper-bound non-dimensional displacements on subsoil groups almost disappears irrespective of the peak ground accelerations, except for $P G A=0.35 \mathrm{~g}$, where the seismic inputs recorded on rock-like subsoil result in a lower non-dimensional displacement $\bar{d}$. In this case, a maximum difference of about $90 \%$ is computed for the non-dimensional displace$\underline{\text { ment }} \bar{d}$ of rock-like (A) and stiff (B) subsoils, at $k_{\mathrm{y}} / k_{\max }=0.8$, for which very low values of $\bar{d}$ are attained. Nonetheless, the curves obtained for the other values of $P G A$ overlap, thus providing the same estimate of the seismic performance.

\subsubsection{Seismic input described via $I_{\mathrm{A}}$ and $k_{\max }$}

The energy content of the seismic input can be introduced in the semi-empirical relationships through the Arias intensity $I_{\mathrm{A}}$ as well, as proposed by Jibson $(1993,2007)$. The relationships adopted in this study are developed for the permanent displacement $d$ only, thus providing relationships $1 \mathrm{~d}, 1 \mathrm{e}$ and $1 \mathrm{f}$ :

$$
\begin{aligned}
& \text { (d) } \log (d)=A_{1 \mathrm{~d}} \cdot \log \left(I_{\mathrm{A}}\right)+B_{1 \mathrm{~d}} \cdot k_{\mathrm{y}}+C_{1 \mathrm{~d}} \pm \sigma \cdot t \\
& \text { (e) } \log (d)=A_{1 \mathrm{e}} \cdot \log \left(I_{\mathrm{A}}\right)+B_{1 \mathrm{e}} \cdot \log \left(k_{\mathrm{y}}\right)+C_{1 \mathrm{e}} \pm \sigma \cdot t
\end{aligned}
$$



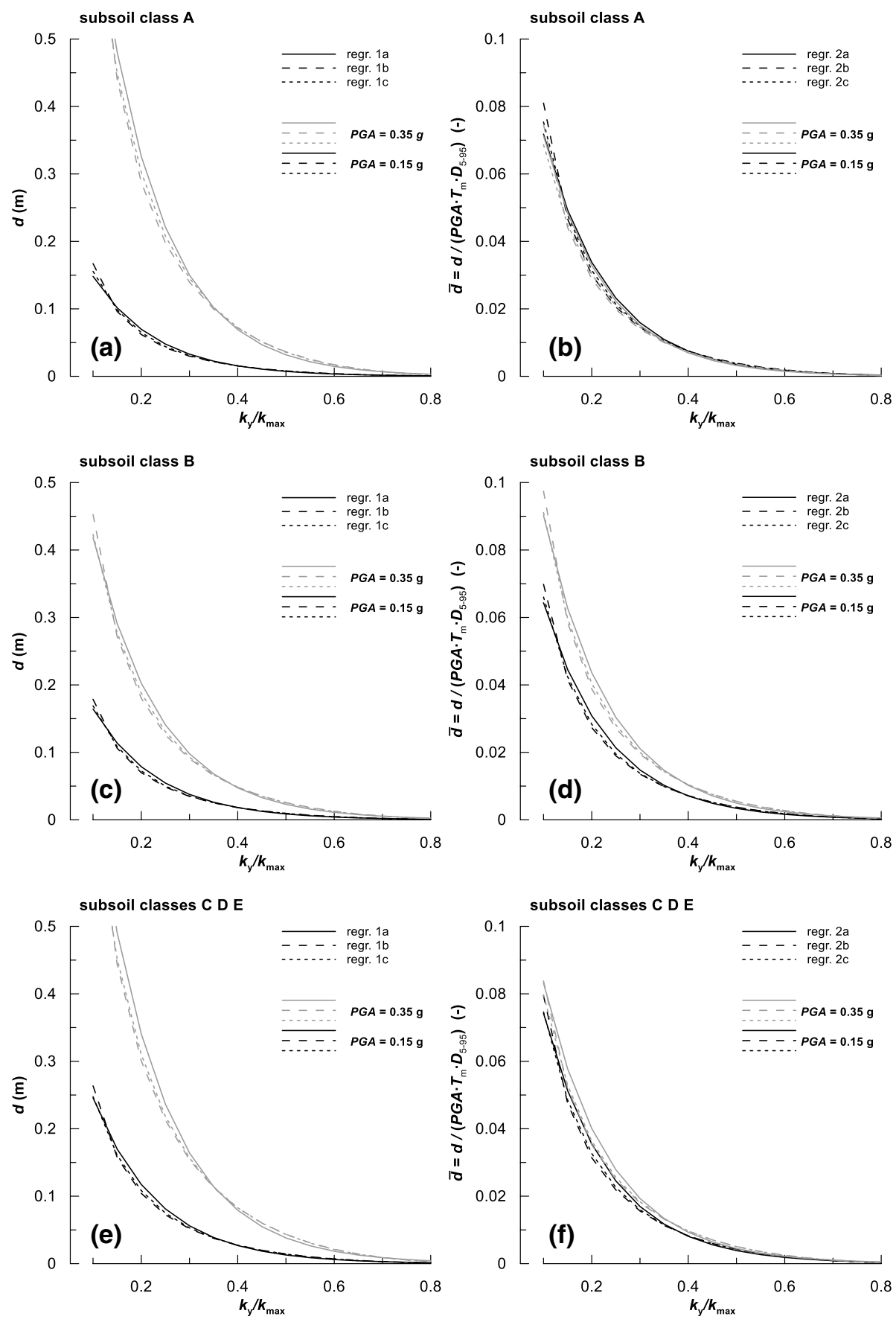

Fig. 15 Comparison between upper-bound (94th percentile) curves obtained using relationships 1 (a, c and e) and 2 (b, d and f) for given values of peak ground accelerations and for all subsoil groups 

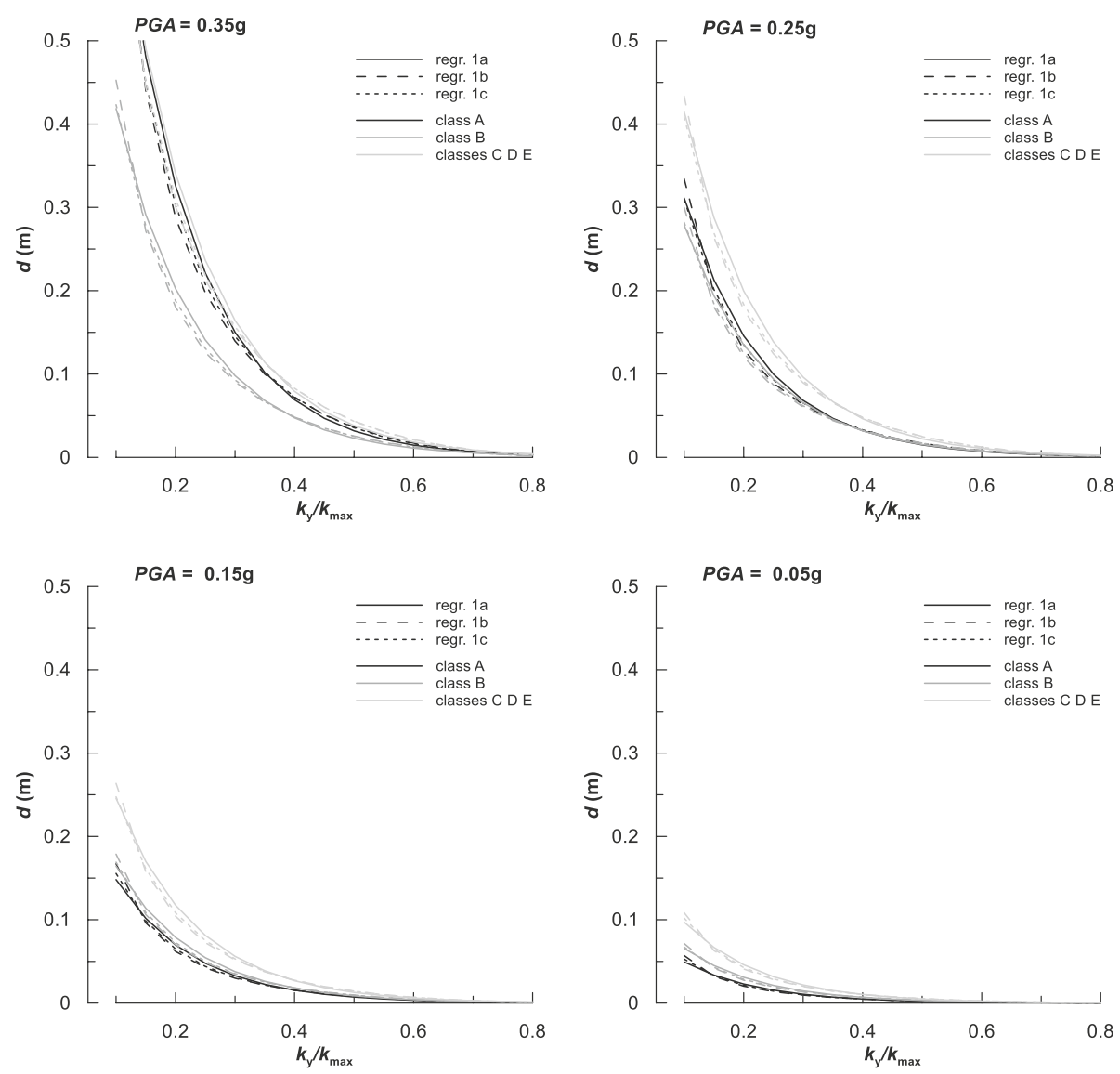

Fig. 16 Influence of the subsoil group on relationships 1 for all considered peak ground acceleration levels

$$
\text { (f) } \log (d)=A_{1 \mathrm{f}} \cdot \log \left(I_{\mathrm{A}}\right)+B_{1 \mathrm{f}} \cdot \log \left(\frac{k_{y}}{k_{\max }}\right)+C_{1 \mathrm{f}} \pm \sigma \cdot t
$$

where $I_{\mathrm{A}}$ is expressed in $\mathrm{m} / \mathrm{s}$ and $d$ in $\mathrm{cm}$. As in Jibson $(1993,2007)$, the curves were obtained without distinguishing between subsoil groups. Values of $I_{\mathrm{A}}=0.2-10.0 \mathrm{~m} / \mathrm{s}$ and $k_{\mathrm{y}}=0.02-0.40$ were considered by Jibson (1993), while values of $I_{\mathrm{A}}=0.002-5.451 \mathrm{~m} / \mathrm{s}$ and $k_{\mathrm{y}}=0.005-0.28$ were considered in this study.

Computed coefficients $A_{\mathrm{i}}, B_{\mathrm{i}}$ and $C_{\mathrm{i}}$, for $i=1 d, 1 e$ and $1 f$, are listed in Tables 6,7 and 8 for relationships given in Eqs. (14), (15) and (16), respectively. These values are also compared to those computed by Jibson $(1993,2007)$. The comparison between the coefficients calculated using relationship $1 d$ (Table 6) shows a similar dependence of permanent displacements $d$ on Arias intensity $I_{\mathrm{A}}$ (coefficient $A_{1 \mathrm{~d}}$ ) but a doubled influence of the yield coefficient $k_{\mathrm{y}}$ (coefficient $B_{1 \mathrm{~d}}$ ); similar results were obtained by Madiai (2009) using an older version of the Italian seismic database (Scasserra et al. 2008). A coefficient $R^{2}=0.674$ was computed for this relationship. Conversely, a better agreement was obtained using the other two relationships (Tables 7 and 8), with higher values of the coefficient of determination $R^{2}>0.81$. 

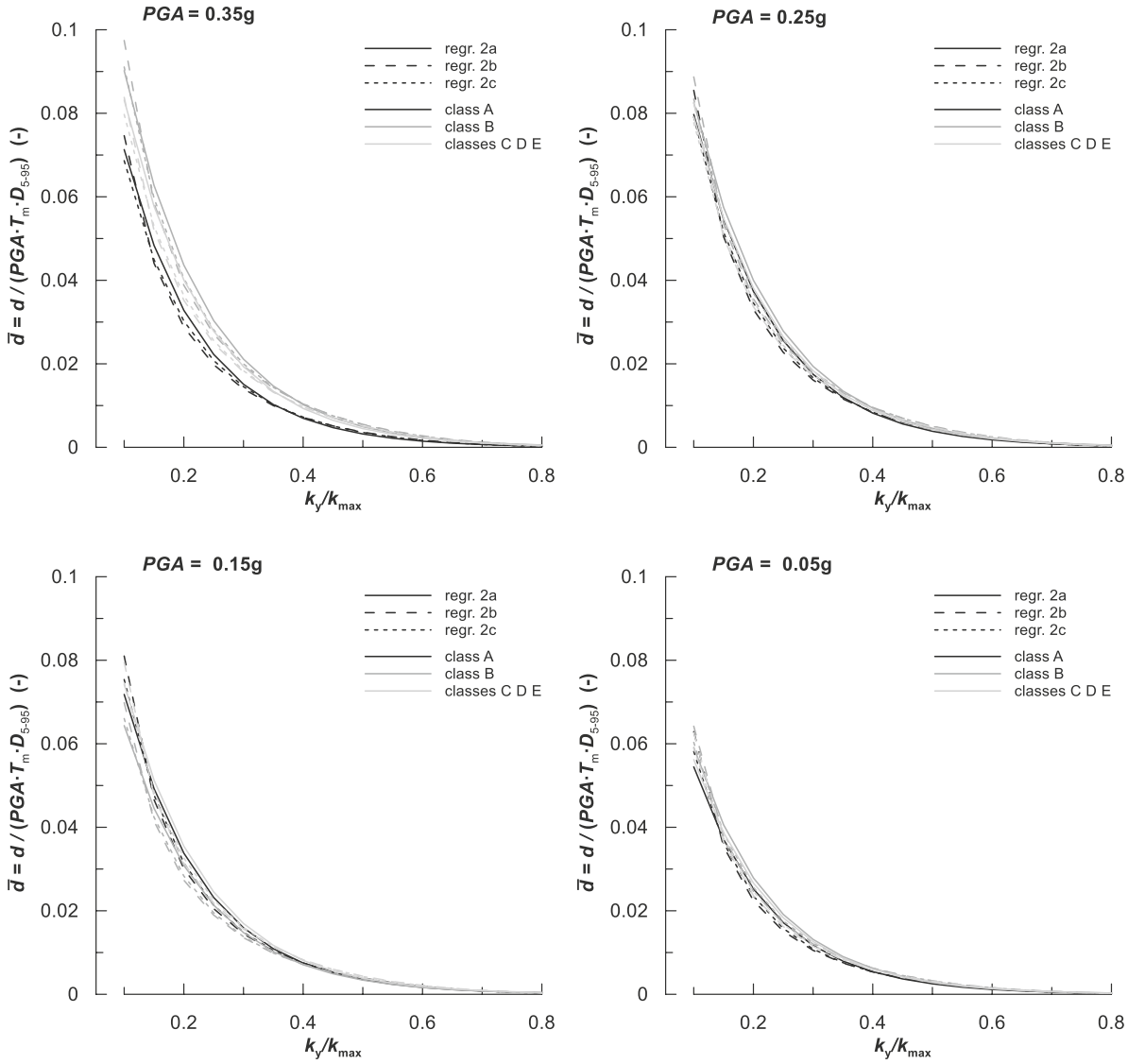

Fig. 17 Influence of the subsoil group on relationships 2 for all considered peak ground acceleration levels

Table 6 Regression relationship $1 d$

\begin{tabular}{lcc}
\hline All subsoil classes & This study & Jibson (1993) \\
\hline$A_{1 \mathrm{~d}}$ & 1.387 & 1.460 \\
$B_{1 \mathrm{~d}}$ & -12.269 & -6.642 \\
$C_{1 \mathrm{~d}}$ & 1.781 & 1.546 \\
$\sigma$ & 0.508 & 0.409 \\
$R^{2}$ & 0.674 & 0.870 \\
\hline
\end{tabular}

Table 7 Regression relationship le

\begin{tabular}{lcc}
\hline All subsoil classes & This study & Jibson (2007) \\
\hline$A_{1 \mathrm{e}}$ & 1.613 & 2.401 \\
$B_{1 \mathrm{e}}$ & -2.256 & -3.481 \\
$C_{1 \mathrm{e}}$ & -1.817 & -3.230 \\
$\sigma$ & 0.382 & 0.656 \\
$R^{2}$ & 0.816 & 0.710 \\
\hline
\end{tabular}


Table 8 Regression relationship If

\begin{tabular}{lcc}
\hline All subsoil classes & This study & Jibson (2007) \\
\hline$A_{1 \mathrm{f}}$ & 0.669 & 0.561 \\
$B_{1 \mathrm{f}}$ & -2.549 & -3.833 \\
$C_{1 \mathrm{f}}$ & -0.924 & -1.474 \\
$\sigma$ & 0.389 & 0.616 \\
$R^{2}$ & 0.819 & 0.750 \\
\hline
\end{tabular}

The upper-bound (94th percentile) relationships $1 d$ (Eq. 14, Table 6) are plotted in Fig. 18a, while Fig. 18b shows the comparison between relationships of type $1 f$ (Eq. 16, Table 8). With reference to Fig. 18a, a fair agreement was obtained for low values of the yield coefficient $k_{\mathrm{y}}(=0.02,0.05$ and 0.10$)$, while lower values of upper-bound displacements were computed for higher values of $k_{\mathrm{y}}(=0.20,0.25$ and 0.28$)$. By contrast, a better agreement is provided by relationships $1 f$ (Fig. 18b) for high ratios $k_{\mathrm{y}} / k_{\max }(=0.60$, 0.70 and 0.80 ), while a poor agreement is observed for low ratios $k_{\mathrm{y}} / k_{\max }$. Again, the observed differences can be attributed to the different databases considered in the analyses. Specifically, Jibson (1993) used 11 strong-motion records from California (10) and Iran (1), while in Jibson (2007) 2270 strong-motion horizontal components, recorded during 30 earthquakes occurred worldwide, were adopted.

\section{Summary and conclusions}

Seismic performance of slopes can be successfully assessed within the framework of the performance-based design, where the seismic-induced permanent displacement $d$ is typically assumed as an index of seismic performance. Permanent displacements induced by earthquake loading can be computed through the well-known Newmark's method, where the slope is assimilated to a rigid-block sliding on a horizontal plane whenever the seismic coefficient $k(t)$ exceeds the yield (or critical) seismic coefficient $k_{\mathrm{y}}$ of the slope at hand.
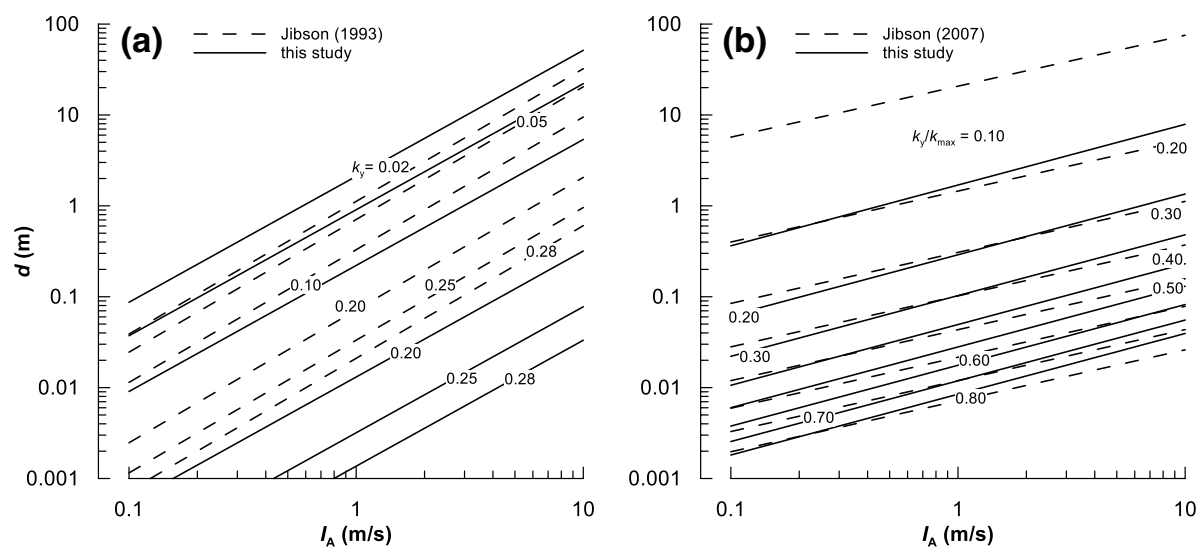

Fig. 18 Upper-bound curves (94th percentile) obtained using relationship $1 d$ (a) and $1 f(\mathbf{b})$ 
In this paper, Newmark-type computations have been performed through a parametrical integration of an updated version of the Italian seismic database. This includes seismic events recorded in the Italian territory in the time frame 1972-2017, thus including the destructive 2009 L'Aquila, 2012 Emilia and 2016 Central Italy earthquakes. It is seen that ground motion parameters characterising the new Italian seismic database, such as the peak ground acceleration $P G A$, the Arias intensity $I_{\mathrm{A}}$, the mean period $T_{\mathrm{m}}$ and the significant duration $D_{5-95}$, can be reasonably computed using, on a first approximation, wellknown ground motion prediction equations (GMPEs) already available in the literature. It is understood that the new database can be used to calibrate new GMPEs as well.

Both one- and two-ground motion parameter, semi-empirical models have been developed following Rathje and Cho (2019), where the permanent displacements are expressed as a function of some parameters of the seismic motion, for a given yield seismic coefficient $k_{\mathrm{y}}$. As expected, two-ground motion parameter relationships are characterised by a higher coefficient of determination $R^{2}$ when accounting for the frequency content and the duration of the seismic motion, in addition to its intensity: among these, the best model, both in terms of accuracy and ease of use, proved to be the ( $P G A, P G V)$ model. These semi-empirical models can be used to evaluate seismic-induced displacements and, in turn, the seismic performance of a slope characterised by a given $k_{\mathrm{y}}$, through the comparison with threshold displacements $d_{\mathrm{y}}$.

The semi-empirical relationships can be modified to explicitly introduce the dependency of slope displacements on the ratio between the yield and the maximum seismic coefficient, $k_{\mathrm{y}} / k_{\max }$. These relationships can be used to either estimate the permanent displacement $d$ induced by earthquake loading or to evaluate the seismic coefficient $k$ to be adopted when using a pseudo-static approach. To this end, upper-bound (94th percentile) relationships linking the permanent displacement $d$ to the ratio $k_{\mathrm{y}} / k_{\max }$ have been proposed and values of the seismic coefficient have been computed assuming threshold displacements $d_{\mathrm{y}}=2,5$ and $15 \mathrm{~cm}$, three subsoil groups (rock, stiff and soft soils) and four acceleration levels $(P G A=0.05,0.15,0.25$ and $0.35 \mathrm{~g}$ ). It is worth mentioning that the procedure laid out in this study to compute the equivalent seismic coefficient can be readily adopted for different values of threshold displacements $d_{\mathrm{y}}$ and for different percentiles. Influence of the vertical component of ground motion on these upper-bound curves has been found to be negligible.

Semi-empirical relationships including additional ground motion parameters provide a better agreement with the permanent displacements computed via the sliding-block analyses: specifically, the best agreement is obtained using the non-dimensional variable $\bar{d}=d /\left[P G A \cdot T_{\mathrm{m}} \cdot D_{5-95}\right]$ and relationship $2 a\left(R_{\max }^{2}=0.86\right)$. However, accounting for the frequency content and duration of the strong motion phase requires an estimate of mean period $T_{\mathrm{m}}$ and significant duration $D_{5-95}$ using the above-mentioned GMPEs, thus introducing further dispersion in the relationship. The seismic input can also be described by the Arias intensity $I_{\mathrm{A}}$ of ground motion, thus providing an additional simplified tool while considering the energy released during the earthquake. The discussed model forms are already well-known in the literature; however, due to the fact that the target of the analyses is evaluating the order of magnitude of permanent displacements instead of their exact value, it is believed that, in this context, increasing the complexity of the analyses by proposing new model forms would not have improved their prediction substantially. Indeed, the updated semi-empirical relationships are meant to be used in the framework of a screen analysis, where sites with expected poor seismic performance are distinguished from those with acceptable seismic performance.

Clearly, some limitations arise in the study. First, the proposed semi-empirical relationships are developed for the Italian seismicity only: nonetheless, the same discussed procedure can be adopted in other high-seismicity areas. Moreover, computation of permanent displacements is based on the simplifying assumptions underlying the adopted 
rigid sliding-block model, such as the one related to a constant shear strength during seismic loading, this possibly leading to underestimate slope displacements. Conversely, neglecting soil deformability results in assuming an infinite wavelength of seismic motion, this leading to overestimate permanent displacements $d$ at the end of the earthquake. The latter assumption explains why the discussed results can be deemed more appropriate for slopes characterised by shallow translational mechanisms.

Acknowledgements The research work presented in this paper was partly funded by the Italian Department of Civil Protection under the ReLUIS research project-Working Package 16: Geotechnical EngineeringTask Group 2: Slope stability

\section{Compliance with ethical standards}

Conflict of interest Authors declare that they have no conflict of interest.

Open Access This article is licensed under a Creative Commons Attribution 4.0 International License, which permits use, sharing, adaptation, distribution and reproduction in any medium or format, as long as you give appropriate credit to the original author(s) and the source, provide a link to the Creative Commons licence, and indicate if changes were made. The images or other third party material in this article are included in the article's Creative Commons licence, unless indicated otherwise in a credit line to the material. If material is not included in the article's Creative Commons licence and your intended use is not permitted by statutory regulation or exceeds the permitted use, you will need to obtain permission directly from the copyright holder. To view a copy of this licence, visit http://creativecommons.org/licenses/by/4.0/.

\section{Appendix 1: Ground motion parameters describing the new seismic database}

Tables 9 and 10 show, for the horizontal and vertical records, the range of peak ground acceleration $P G A$, velocity $P G V$ and displacement $P G D$, together with the mean period $T_{\mathrm{m}}$ (Rathje et al. 1998), the significant duration $D_{5-95}$ (Trifunac et al. 1975), the Arias intensity $I_{\mathrm{A}}$ (Arias, 1970), and the zero-crossings frequency, $v_{(0)}$, the latter estimated during the strong-motion phase. Maximum values of peak ground acceleration $P G A=0.867 \mathrm{~g}$, velocity $P G V=83.02 \mathrm{~cm} / \mathrm{s}$, displacement $P G D=26.87 \mathrm{~cm}$, and Arias intensity $I_{\mathrm{A}}=608.7 \mathrm{~cm} / \mathrm{s}$ are obtained for the horizontal records (Table 9), while mean periods $T_{\mathrm{m}}$ of 0.066 to $1.55 \mathrm{~s}$, significant durations $D_{5-95}=0.4-53.0 \mathrm{~s}$ and zerocrossing frequencies $\nu_{(0)}=1.93$ to $50.52 \mathrm{~Hz}$ are computed.

The vertical component of the seismic records (Table 10) is characterised by maximum values of peak ground acceleration $P G A=0.886 \mathrm{~g}$ and significant duration $D_{5-95}=54.2 \mathrm{~s}$ similar to those obtained for the horizontal components. Frequency content of the vertical component is instead richer in high frequencies, this providing a lower value of the maximum mean period $T_{\mathrm{m}}=1.349 \mathrm{~s}$ and a larger value of the zero-crossing frequency $\nu_{(0)}=62.28 \mathrm{~Hz}$. Lower values of maximum peak velocity $P G V=68.62 \mathrm{~cm} / \mathrm{s}$ and Arias intensity $I_{\mathrm{A}}=474.6 \mathrm{~cm} / \mathrm{s}$ are also obtained, together with a higher maximum peak displacement $P G D=37.08 \mathrm{~cm}$. 
Table 9 Ground motion parameters of the horizontal component of seismic records

\begin{tabular}{llllllll}
\hline Subsoil class & $P G A(\mathrm{~g})$ & $P G V(\mathrm{~cm} / \mathrm{s})$ & $P G D(\mathrm{~cm})$ & $T_{\mathrm{m}}(\mathrm{s})$ & $D_{5-95}(\mathrm{~s})$ & $I_{\mathrm{A}}(\mathrm{cm} / \mathrm{s})$ & $\nu_{(0)}(\mathrm{Hz})$ \\
\hline$A$ & $0.053-0.186$ & $1.39-21.44$ & $0.17-11.85$ & $0.116-1.179$ & $1.1-49.8$ & $1.0-28.7$ & $3.46-29.57$ \\
$A^{*}$ & $0.050-0.866$ & $0.72-66.08$ & $0.01-14.92$ & $0.078-0.804$ & $0.8-53.0$ & $0.3-608.7$ & $3.41-34.54$ \\
$A+A^{*}$ & $0.050-0.866$ & $0.72-66.08$ & $0.01-14.92$ & $0.078-1.179$ & $0.8-53.0$ & $0.3-608.7$ & $3.41-34.54$ \\
$B$ & $0.050-0.657$ & $0.54-70.32$ & $0.02-26.87$ & $0.066-1.550$ & $0.4-49.5$ & $0.4-362.8$ & $1.93-50.52$ \\
$B^{*}$ & $0.050-0.867$ & $0.60-83.02$ & $0.02-21.28$ & $0.080-0.987$ & $0.5-48.7$ & $0.3-384.2$ & $4.49-37.57$ \\
$B+B^{*}$ & $0.050-0.867$ & $0.54-83.02$ & $0.02-26.87$ & $0.066-1.55$ & $0.4-49.5$ & $0.3-384.2$ & $1.93-50.52$ \\
$C$ & $0.050-0.41$ & $1.06-57.51$ & $0.06-14.21$ & $0.130-1.265$ & $1.6-49.3$ & $0.6-132.6$ & $2.93-24.62$ \\
$C^{*}$ & $0.050-0.72$ & $0.76-58.52$ & $0.02-23.02$ & $0.096-1.207$ & $0.7-52.8$ & $0.5-288.8$ & $3.29-45.23$ \\
$C+C^{*}$ & $0.050-0.72$ & $0.76-58.52$ & $0.02-23.02$ & $0.096-1.265$ & $0.7-52.8$ & $0.5-288.8$ & $2.93-45.23$ \\
$D$ & $0.057-0.338$ & $3.37-22.86$ & $0.41-4.21$ & $0.268-1.049$ & $3.0-37.9$ & $2.6-69.7$ & $2.87-13.11$ \\
$E$ & $0.050-0.531$ & $0.94-32.57$ & $0.03-5.43$ & $0.099-0.364$ & $1.1-13.8$ & $0.9-286.7$ & $7.04-34.74$ \\
All & $0.050-0.867$ & $0.54-83.02$ & $0.01-26.87$ & $0.066-1.550$ & $0.4-53.0$ & $0.3-608.7$ & $1.93-50.52$ \\
\hline
\end{tabular}

Table 10 Ground motion parameters of the vertical component of seismic records

\begin{tabular}{|c|c|c|c|c|c|c|c|}
\hline $\begin{array}{l}\text { Subsoil } \\
\text { class }\end{array}$ & $P G A(\mathrm{~g})$ & $P G V(\mathrm{~cm} / \mathrm{s})$ & $P G D(\mathrm{~cm})$ & $T_{\mathrm{m}}(\mathrm{s})$ & $D_{5-95}(\mathrm{~s})$ & $I_{\mathrm{A}}(\mathrm{cm} / \mathrm{s})$ & $\nu_{(0)}(\mathrm{Hz})$ \\
\hline$A$ & $0.017-0.105$ & $0.72-13.24$ & $0.06-8.32$ & $0.136-1.349$ & $1.9-53$ & $0.22-15.3$ & $33.75-21.29$ \\
\hline$A^{*}$ & $0.011-0.886$ & $0.23-68.62$ & $0.01-37.08$ & $0.09-0.843$ & $1.2-53.1$ & $0.07-474.6$ & $6 \quad 7.7-37.19$ \\
\hline$A+A^{*}$ & $0.011-0.886$ & $0.23-68.62$ & $0.01-37.08$ & 0.09-1.349 & $1.2-53.1$ & $0.07-474.6$ & $63.75-37.19$ \\
\hline$B$ & $\begin{array}{l}0.00002- \\
0.496\end{array}$ & $0.002-25.6$ & $0.0002-16.84$ & $0.073-1.069$ & $0.7-52.6$ & $\begin{array}{l}0.000002- \\
181.4\end{array}$ & $2.95-62.28$ \\
\hline$B^{*}$ & $0.007-0.645$ & $0.11-33.7$ & $0.004-21.13$ & $30.069-1.127$ & $0.5-50.6$ & $0.02-153.5$ & $5.31-46.24$ \\
\hline$B+B^{*}$ & $\begin{array}{l}0.00002- \\
0.645\end{array}$ & $0.002-33.7$ & $0.0002-21.13$ & $0.069-1.127$ & $0.5-52.6$ & $\begin{array}{l}0.000002- \\
181.4\end{array}$ & $2.95-62.28$ \\
\hline$C$ & $0.008-0.857$ & 7 $0.29-26.77$ & $0.02-5.8$ & $0.097-1.337$ & $2.1-45.6$ & $0.06-305.3$ & $34.52-32.92$ \\
\hline$C^{*}$ & $0.008-0.729$ & $0.15-24.93$ & $0.006-11.35$ & $0.074-1.27$ & $0.7-54.2$ & $0.07-225.2$ & $24.34-49.9$ \\
\hline$C+C^{*}$ & $0.008-0.857$ & $0.15-26.77$ & $0.006-11.35$ & $0.074-1.337$ & $0.7-54.2$ & $0.06-305.3$ & $34.34-49.9$ \\
\hline$D$ & $0.026-0.24$ & $2.27-10.82$ & $0.18-2.1$ & $0.208-0.565$ & $5-37.3$ & $0.9-34.8$ & 14.05 \\
\hline$E$ & $0.009-0.444$ & $0.22-21.22$ & $0.01-2.74$ & $0.107-0.369$ & $1.2-15.6$ & $0.05-65.0$ & $7.83-46.04$ \\
\hline All & $\begin{array}{l}0.00002- \\
0.886\end{array}$ & $0.002-68.62$ & $0.0002-37.08$ & 30.069-1.349 & $0.5-54.2$ & $\begin{array}{l}0.000002- \\
474.6\end{array}$ & $2.95-62.28$ \\
\hline
\end{tabular}

\section{Appendix 2 : Coefficients for the semi-empirical relationships of Sect. 4.3.1}

Coefficients $A, B, C$ and $D$ characterising the different regressions are given in Tables $11,12,13,14,15,16$ with a double subscript that identifies the functional form $(a, b$, $c$ ) and the dependent variable $(1,2)$. The coefficients calculated for each empirical relationship are listed together with the standard deviation $\sigma$ and the coefficient of determination $R^{2}$, for each subsoil group and acceleration level. 
Table 11 Regression relationship $1 a$

Table 12 Regression relationship $2 a$

\begin{tabular}{lrrrr}
\hline Subsoil class $A$ & $0.05 \mathrm{~g}$ & $0.15 \mathrm{~g}$ & $0.25 \mathrm{~g}$ & $0.35 \mathrm{~g}$ \\
\hline$A_{1 \mathrm{a}}(\mathrm{cm})$ & -3.342 & -3.273 & -3.294 & -3.371 \\
$B_{1 \mathrm{a}}(\mathrm{cm})$ & 0.414 & 0.858 & 1.161 & 1.434 \\
$\sigma(\mathrm{cm})$ & 0.394 & 0.411 & 0.426 & 0.485 \\
$R^{2}$ & 0.770 & 0.747 & 0.737 & 0.694 \\
Subsoil class $B$ & $0.05 \mathrm{~g}$ & $0.15 \mathrm{~g}$ & $0.25 \mathrm{~g}$ & $0.35 \mathrm{~g}$ \\
$A_{1 \mathrm{a}}(\mathrm{cm})$ & -3.265 & -3.195 & -3.146 & -3.154 \\
$B_{1 \mathrm{a}}(\mathrm{cm})$ & 0.468 & 0.872 & 1.052 & 1.204 \\
$\sigma(\mathrm{cm})$ & 0.434 & 0.427 & 0.455 & 0.472 \\
$R^{2}$ & 0.725 & 0.723 & 0.691 & 0.676 \\
Subsoil group $C D E$ & $0.05 \mathrm{~g}$ & $0.15 \mathrm{~g}$ & $0.25 \mathrm{~g}$ & $0.35 \mathrm{~g}$ \\
$A_{1 \mathrm{a}}(\mathrm{cm})$ & -3.245 & -3.207 & -3.174 & -3.170 \\
$B_{1 \mathrm{a}}(\mathrm{cm})$ & 0.538 & 0.991 & 1.234 & 1.443 \\
$\sigma(\mathrm{cm})$ & 0.497 & 0.463 & 0.451 & 0.465 \\
$R^{2}$ & 0.665 & 0.691 & 0.698 & 0.684 \\
\hline
\end{tabular}

\begin{tabular}{lrrrr}
\hline Subsoil class $A$ & \multicolumn{1}{c}{$0.05 \mathrm{~g}$} & \multicolumn{1}{c}{$0.15 \mathrm{~g}$} & \multicolumn{1}{c}{$0.25 \mathrm{~g}$} & \multicolumn{1}{c}{$0.35 \mathrm{~g}$} \\
\hline$A_{2 \mathrm{a}}$ & -3.342 & -3.273 & -3.294 & -3.371 \\
$B_{2 \mathrm{a}}$ & -1.447 & -1.402 & -1.283 & -1.269 \\
$\sigma$ & 0.333 & 0.377 & 0.331 & 0.295 \\
$R^{2}$ & 0.825 & 0.779 & 0.823 & 0.859 \\
Subsoil class $B$ & $0.05 \mathrm{~g}$ & $0.15 \mathrm{~g}$ & $0.25 \mathrm{~g}$ & $0.35 \mathrm{~g}$ \\
$A_{2 \mathrm{a}}$ & -3.265 & -3.195 & -3.146 & -3.154 \\
$B_{2 \mathrm{a}}$ & -1.395 & -1.379 & -1.342 & -1.325 \\
$\sigma$ & 0.317 & 0.326 & 0.369 & 0.383 \\
$R^{2}$ & 0.832 & 0.818 & 0.773 & 0.760 \\
Subsoil group $C D E$ & $0.05 \mathrm{~g}$ & $0.15 \mathrm{~g}$ & $0.25 \mathrm{~g}$ & $0.35 \mathrm{~g}$ \\
$A_{2 \mathrm{a}}$ & -3.245 & -3.207 & -3.174 & -3.170 \\
$B_{2 \mathrm{a}}$ & -1.447 & -1.373 & -1.317 & -1.254 \\
$\sigma$ & 0.335 & 0.362 & 0.343 & 0.316 \\
$R^{2}$ & 0.814 & 0.785 & 0.800 & 0.825 \\
\hline
\end{tabular}


Table 13 Regression relationship $1 b$

\begin{tabular}{lrrrr}
\hline Subsoil class $A$ & $0.05 \mathrm{~g}$ & $0.15 \mathrm{~g}$ & $0.25 \mathrm{~g}$ & $0.35 \mathrm{~g}$ \\
\hline$A_{1 \mathrm{~b}}(\mathrm{~cm})$ & 2.347 & 2.346 & 2.472 & 2.584 \\
$B_{1 \mathrm{~b}}(\mathrm{~cm})$ & -1.090 & -1.032 & -0.953 & -0.934 \\
$C_{1 \mathrm{~b}}(\mathrm{~cm})$ & -0.838 & -0.339 & 0.024 & 0.304 \\
$\sigma(\mathrm{cm})$ & 0.393 & 0.410 & 0.424 & 0.484 \\
$R^{2}$ & 0.772 & 0.749 & 0.739 & 0.696 \\
Subsoil class $B$ & $0.05 \mathrm{~g}$ & $0.15 \mathrm{~g}$ & $0.25 \mathrm{~g}$ & $0.35 \mathrm{~g}$ \\
$A_{1 \mathrm{~b}}(\mathrm{~cm})$ & 2.418 & 2.364 & 2.349 & 2.345 \\
$B_{1 \mathrm{~b}}(\mathrm{~cm})$ & -0.971 & -0.952 & -0.921 & -0.930 \\
$C_{1 \mathrm{~b}}(\mathrm{~cm})$ & -0.679 & -0.252 & -0.041 & 0.102 \\
$\sigma(\mathrm{cm})$ & 0.432 & 0.425 & 0.453 & 0.470 \\
$R^{2}$ & 0.728 & 0.726 & 0.693 & 0.678 \\
Subsoil group $C D E$ & $0.05 \mathrm{~g}$ & $0.15 \mathrm{~g}$ & $0.25 \mathrm{~g}$ & $0.35 \mathrm{~g}$ \\
$A_{1 \mathrm{~b}}(\mathrm{~cm})$ & 2.346 & 2.405 & 2.434 & 2.502 \\
$B_{1 \mathrm{~b}}(\mathrm{~cm})$ & -1.008 & -0.931 & -0.880 & -0.826 \\
$C_{1 \mathrm{~b}}(\mathrm{~cm})$ & -0.636 & -0.117 & 0.171 & 0.423 \\
$\sigma(\mathrm{cm})$ & 0.496 & 0.461 & 0.449 & 0.463 \\
$R^{2}$ & 0.667 & 0.694 & 0.701 & 0.688 \\
\hline & & & &
\end{tabular}

Table 14 Regression relationship $2 b$

\begin{tabular}{lrrrr}
\hline Subsoil class $A$ & $0.05 \mathrm{~g}$ & \multicolumn{1}{c}{$0.15 \mathrm{~g}$} & $0.25 \mathrm{~g}$ & $0.35 \mathrm{~g}$ \\
\hline$A_{2 \mathrm{~b}}$ & 2.347 & 2.346 & 2.472 & 2.584 \\
$B_{2 \mathrm{~b}}$ & -1.090 & -1.032 & -0.953 & -0.934 \\
$C_{2 \mathrm{~b}}$ & -2.700 & -2.600 & -2.420 & -2.399 \\
$\sigma$ & 0.332 & 0.375 & 0.329 & 0.293 \\
$R^{2}$ & 0.826 & 0.781 & 0.825 & 0.862 \\
Subsoil class $B$ & $0.05 \mathrm{~g}$ & $0.15 \mathrm{~g}$ & $0.25 \mathrm{~g}$ & $0.35 \mathrm{~g}$ \\
$A_{2 \mathrm{~b}}$ & 2.418 & 2.364 & 2.349 & 2.345 \\
$B_{2 \mathrm{~b}}$ & -0.971 & -0.952 & -0.921 & -0.930 \\
$C_{2 \mathrm{~b}}$ & -2.542 & -2.502 & -2.435 & -2.426 \\
$\sigma$ & 0.314 & 0.323 & 0.367 & 0.381 \\
$R^{2}$ & 0.835 & 0.821 & 0.775 & 0.762 \\
Subsoil group $C D E$ & $0.05 \mathrm{~g}$ & $0.15 \mathrm{~g}$ & $0.25 \mathrm{~g}$ & $0.35 \mathrm{~g}$ \\
$A_{2 \mathrm{~b}}$ & 2.346 & 2.405 & 2.434 & 2.502 \\
$B_{2 \mathrm{~b}}$ & -1.008 & -0.931 & -0.880 & -0.826 \\
$C_{2 \mathrm{~b}}$ & -2.621 & -2.481 & -2.381 & -2.274 \\
$\sigma$ & 0.333 & 0.360 & 0.340 & 0.312 \\
$R^{2}$ & 0.817 & 0.788 & 0.803 & 0.829 \\
\hline
\end{tabular}


Table 15 Regression relationship 1c

\begin{tabular}{lrrrr}
\hline Subsoil class $A$ & \multicolumn{1}{c}{$0.05 \mathrm{~g}$} & \multicolumn{1}{c}{$0.15 \mathrm{~g}$} & $0.25 \mathrm{~g}$ & \multicolumn{1}{c}{$0.35 \mathrm{~g}$} \\
\hline$A_{1 \mathrm{c}}(\mathrm{cm})$ & -4.209 & -4.203 & -3.772 & -3.577 \\
$B_{1 \mathrm{c}}(\mathrm{cm})$ & 5.335 & 5.228 & 4.412 & 4.019 \\
$C_{1 \mathrm{c}}(\mathrm{cm})$ & -5.236 & -5.074 & -4.658 & -4.516 \\
$D_{1 \mathrm{c}}(\mathrm{cm})$ & 0.586 & 1.014 & 1.256 & 1.499 \\
$\sigma(\mathrm{cm})$ & 0.393 & 0.410 & 0.424 & 0.484 \\
$R^{2}$ & 0.772 & 0.749 & 0.739 & 0.697 \\
Subsoil class $B$ & $0.05 \mathrm{~g}$ & $0.15 \mathrm{~g}$ & $0.25 \mathrm{~g}$ & $0.35 \mathrm{~g}$ \\
$A_{1 \mathrm{c}}(\mathrm{cm})$ & -4.355 & -4.443 & -4.100 & -3.926 \\
$B_{1 \mathrm{c}}(\mathrm{cm})$ & 5.269 & 5.402 & 4.904 & 4.688 \\
$C_{1 \mathrm{c}}(\mathrm{cm})$ & -4.998 & -4.986 & -4.726 & -4.660 \\
$D_{1 \mathrm{c}}(\mathrm{cm})$ & 0.606 & 1.017 & 1.174 & 1.319 \\
$\sigma(\mathrm{cm})$ & 0.432 & 0.425 & 0.453 & 0.470 \\
$R^{2}$ & 0.728 & 0.726 & 0.693 & 0.678 \\
Subsoil group $C D E$ & $0.05 \mathrm{~g}$ & $0.15 \mathrm{~g}$ & $0.25 \mathrm{~g}$ & $0.35 \mathrm{~g}$ \\
$A_{1 \mathrm{c}}(\mathrm{cm})$ & -4.420 & -4.138 & -4.066 & -4.247 \\
$B_{1 \mathrm{c}}(\mathrm{cm})$ & 5.482 & 4.923 & 4.716 & 4.807 \\
$C_{1 \mathrm{c}}(\mathrm{cm})$ & -5.124 & -4.778 & -4.608 & -4.562 \\
$D_{1 \mathrm{c}}(\mathrm{cm})$ & 0.699 & 1.109 & 1.331 & 1.526 \\
$\sigma(\mathrm{cm})$ & 0.496 & 0.461 & 0.449 & 0.463 \\
$R^{2}$ & 0.667 & 0.694 & 0.701 & 0.688 \\
\hline
\end{tabular}

Table 16 Regression relationship $2 c$

\begin{tabular}{lrrrr}
\hline Subsoil class $A$ & $0.05 \mathrm{~g}$ & \multicolumn{1}{c}{$0.15 \mathrm{~g}$} & $0.25 \mathrm{~g}$ & \multicolumn{1}{c}{$0.35 \mathrm{~g}$} \\
\hline$A_{2 \mathrm{c}}$ & -4.209 & -4.203 & -3.772 & -3.577 \\
$B_{2 \mathrm{c}}$ & 5.335 & 5.228 & 4.412 & 4.019 \\
$C_{2 \mathrm{c}}$ & -5.236 & -5.074 & -4.658 & -4.516 \\
$D_{2 \mathrm{c}}$ & -1.276 & -1.247 & -1.187 & -1.204 \\
$\sigma$ & 0.331 & 0.375 & 0.329 & 0.293 \\
$R^{2}$ & 0.827 & 0.781 & 0.826 & 0.862 \\
Subsoil class $B$ & $0.05 \mathrm{~g}$ & $0.15 \mathrm{~g}$ & $0.25 \mathrm{~g}$ & $0.35 \mathrm{~g}$ \\
$A_{2 \mathrm{c}}$ & -4.355 & -4.443 & -4.100 & -3.926 \\
$B_{2 \mathrm{c}}$ & 5.269 & 5.402 & 4.904 & 4.688 \\
$C_{2 \mathrm{c}}$ & -4.998 & -4.986 & -4.726 & -4.660 \\
$D_{2 \mathrm{c}}$ & -1.257 & -1.234 & -1.221 & -1.210 \\
$\sigma$ & 0.314 & 0.323 & 0.366 & 0.381 \\
$R^{2}$ & 0.835 & 0.821 & 0.775 & 0.763 \\
Subsoil group $C D E$ & $0.05 \mathrm{~g}$ & $0.15 \mathrm{~g}$ & $0.25 \mathrm{~g}$ & $0.35 \mathrm{~g}$ \\
$A_{2 \mathrm{c}}$ & -4.420 & -4.138 & -4.066 & -4.247 \\
$B_{2 \mathrm{c}}$ & 5.482 & 4.923 & 4.716 & 4.807 \\
$C_{2 \mathrm{c}}$ & -5.124 & -4.778 & -4.608 & -4.562 \\
$D_{2 \mathrm{c}}$ & -1.285 & -1.254 & -1.220 & -1.171 \\
$\sigma$ & 0.333 & 0.360 & 0.340 & 0.312 \\
$R^{2}$ & 0.817 & 0.788 & 0.804 & 0.829 \\
\hline
\end{tabular}




\section{References}

Ambraseys NN, Douglas J, Sarma SK, Smit PM (2005) Equations for the estimation of strong ground motion from shallow crustal earthquakes using data from Europe and the Middle East: horizontal peak ground acceleration and spectral acceleration. Bull Earthq Eng 3:1-53

Ambraseys NN, Menu JM (1988) Earthquake-induced ground displacement. Earthq Eng Struct Dynam 16(7):985-1006. https://doi.org/10.1002/eqe.4290160704

Arias A (1970) A measure of earthquake intensity. In: Hansen R (ed) Seismic design for nuclear power plants. The MIT Press, Cambridge, pp 438-483

Ausilio E, Conte E, Dente G (2000) Seismic stability of reinforced slopes. Soil Dyn Earthq Eng 19(3):159-172

Bandini V, Biondi G, Cascone E, Rampello S (2015) A GLE-based model for seismic displacement analysis of slopes. Soil Dyn Earthq Eng 71:128-142

Biondi G, Cascone E, Maugeri M (2014) Displacement versus pseudo-static evaluation of the seismic performance of sliding retaining walls. Bull Earthq Eng 12(3):1239-1267. https://doi.org/10.1007/s1051 8-013-9542-4

Biondi G, Cascone E, Rampello S (2011) Valutazione del comportamento dei pendii in condizioni sismiche. Rivista Italiana di Geotecnica XLV(1):9-32 (in Italian)

Bray JD, Macedo J, Travasarou T (2017) Simplified procedure for estimating seismic slope displacements for subduction zone earthquakes. J Geotech Geoenviron Eng 144(3):04017124

Bray JD, Rathje EM, Augello AJ, Merry SM (1998) Simplified seismic design procedure for geosyntheticlined, solid-wasteland fills. Geosynthetics International 5(1-2):203-235

Bray JD, Travasarou T (2009) Pseudostatic coefficient for use in simplified seismic slope stability evaluation. J Geotech Geoenviron Eng 135(9):1336-1340

Campbell KW, Bozorgnia Y (2012) A comparison of ground motion prediction equations for Arias intensity and cumulative absolute velocity developed using a consistent database and functional form. Earthq Spectra 28(3):931-941

CEN (Comité Européen de Normalisation) (2003) prEN 1998-1- Eurocode 8: design of structures for earthquake resistance. Part 1: General rules, seismic actions and rules for buildings. Draft No 6, Doc CEN/ TC250/SC8/N335, January 2003, Brussels.

Chousianitis K, Del Gaudio V, Kalogeras I, Ganas A (2014) Predictive model of Arias intensity and Newmark displacement for regional scale evaluation of earthquake-induced landslide hazard in Greece. Soil Dyn Earthq Eng 65:11-29

Crespellani N, Madiai C, Vannucchi G (1998) Earthquake destructiveness potential factor and slope stability. Géotechnique 48(3):411-419

de Nardis R, Filippi L, Costa G, Suhadolc P, Nicoletti M, Lavecchia G (2014) Strong motion recorded during the Emilia 2012 thrust earthquakes (Northern Italy): a comprehensive analysis. Bull Earthq Eng. https://doi.org/10.1007/s10518-014-9614-0

Di Filippo G, Biondi G, Cascone E (2019) Influence of earthquake-induced pore-water pressure on the seismic stability of cohesive slopes. In: Proceedings of the 7 th international conference on earthquake geotechnical engineering, Rome, Italy, 2019:1-9.

Douglas J (2012) Consistency of ground-motion predictions from the past four decades: peak ground velocity and displacement, Arias intensity and relative significant duration. Bull Earthq Eng 10(5):13391356. https://doi.org/10.1007/s10518-012-9359-6

Du W, Wang G (2016) A one-step Newmark displacement model for probabilistic seismic slope displacement hazard analysis. Eng Geol 205:12-23

Felicetta C, D’Amico M, Lanzano G, Puglia R, Russo E, Luzi L (2017) Site characterization of Italian accelerometric stations. Bull Earthq Eng 15(6):2329-2348. https://doi.org/10.1007/s10518-016-9942-3

Fotopoulou S, Pitilakis K (2015) Predictive relationships for seismically induced slope displacements using numerical analysis results. Bull Earthq Eng 13(11):3207-3238

Gaudio D, Masini L, Rampello S (2018a) A performance-based approach to design reinforced-earth retaining walls. Geotext Geomembr 46(4):470-485. https://doi.org/10.1016/j.geotexmem.2018.04.003

Gaudio D, Masini L, Rampello S (2018b) Seismic performance of geosynthetic-reinforced earth retaining walls subjected to strong ground motions. In: Proceedings of the China-Europe conference on geotechnical engineering, Aug 13-16, 2018, Vienna, Austria. Springer Series in Geomechanics and Geoengineering 216849, pp 1474-1478. https://doi.org/10.1007/978-3-319-97115-5-126

Gaudio D, Masini L, Rampello S (2021) A procedure to design geosynthetic-reinforced earth-retaining walls under seismic loadings. In: Proceedings of the international conference of the association for computer methods and advances in geomechanics, May 05-08, 2021, Turin, Italy. Springer 
Gazetas G, Garini E, Anastasopoulos I, Georgarakos T (2009) Effects of near-fault ground shaking on sliding systems. J Geotech Geoenviron Eng 135(12):1906-1921

Hynes-Griffin ME, Franklin AG (1984) Rationalizing the seismic coefficient method, US army corps of engineers waterways experiment station, miscellaneous paper vol. GL-84-13.

Idriss IM (1985) Evaluating seismic risk in engineering practice. In: Proceedings of the eleventh international conference on soil mechanics and foundation engineering, San Francisco, CA, pp 255-320

Ji J, Zhang W, Zhang F, Gao Y, Lü Q (2020) Reliability analysis on permanent displacement of earth slopes using the simplified bishop method. Comp Geotech 117:103286

Jibson RW (1993) Predicting earthquake-induced landslide displacements using Newmark's sliding block analysis. Transp Res Rec 1411:9-17

Jibson RW (2007) Regression models for estimating coseismic landslide displacement. Eng Geol 91(2-4):209-218

Joyner WB, Boore DM (1981) Peak horizontal acceleration and velocity from strong-motion records including records from the 1979 Imperial Valley, California, earthquake. Bull Seismol Soc Am 71(6):2011-2038

Kayen RE, Mitchell JK (1997) Assessment of liquefaction potential during earthquakes by Arias intensity. J Geotech Geoenviron Eng 123(12):1162-1175

Keefer DK, Wilson R (1989) Predicting earthquake-induced landslides, with emphasis on arid and semiarid environments. In: Sadler P, Morton D, Inland Geological Society (eds) Landslides in a semiarid environment: with emphasis on the inland valleys of southern California. Publications of the Inland Geological Society, Inland Geological Society, Riverside

Kempton JJ, Stewart JP (2006) Prediction equations for significant duration of earthquake ground motions considering site and near-source effects. Earthq Spectra 22(4):985-1013. https://doi. org/10.1193/1.2358175

Lanzano G, Puglia R, Russo E, Luzi L, Bindi D, Cotton F, D’Amico M, Felicetta C, Pacor F, ORFEUS WG5 (2017) ESM strong-motion flat-file 2017. Istituto Nazionale di Geofisica e Vulcanologia (INGV), Helmholtz-Zentrum Potsdam Deutsches GeoForschungsZentrum (GFZ), Observatories \& Research Facilities for European Seismology (ORFEUS). PID: 11099/ ESM_6269e409-ea78-4a00-bbee-14d0e3c39e41_flatfile_2017

Luzi L, Pacor F, Lanzano G, Felicetta C, Puglia R, D’Amico M (2019) 2016-2017 Central Italy seismic sequence: strong-motion data analysis and design earthquake selection for seismic microzonation purposes. Bull Earthq Eng:1-19.

Luzi L, Pacor F, Puglia R (2016a) Italian Accelerometric Archive v 2.1. Istituto Nazionale di Geofisica e Vulcanologia, Dipartimento della Protezione Civile Nazionale. https://doi.org/10.13127/ITACA/2.1

Luzi L, Puglia R, Russo E, ORFEUS WG5 (2016b). Engineering strong motion database, version 1.0. Istituto Nazionale di Geofisica e Vulcanologia, Observatories \& Research Facilities for European Seismology. https://doi.org/10.13127/ESM

Macedo J, Bray J, Abrahamson N, Travasarou T (2018) Performance-based probabilistic seismic slope displacement procedure. Earthq Spectra 34(2):673-695. https://doi.org/10.1193/122516EQS251M

Macedo J, Candia G (2020) Performance-based assessment of the seismic pseudo-static coefficient used in slope stability analysis. Soil Dyn Earthq Eng 133:106109

Madiai C (2009) Correlazioni tra parametri del moto sismico e spostamenti attesi del blocco di Newmark. Rivista Italiana di Geotecnica 1(09):23-43 (in Italian)

Malagnini L, Montaldo V (2004) Relazioni di attenuazione del moto del suolo App.3 al Rapporto Conclusivo Redazione della mappa di pericolosità sismica (Ordinanza PCM 20.03.03, n.3274). Istituto Nazionale di Geofisica e Vulcanologia.

Maugeri M, Simonelli AL, Ferraro A, Grasso S (2011) Recorded ground motion and site effects evaluation for the April 6, 2009 L'Aquila earthquake. Bull Earthq Eng 9:157-179

Michalowski R, Li Y (2000) Displacements of reinforced slopes subjected to seismic loads. J Geotech Geoenviron Eng 126(8):685-694

Ministero delle Infrastrutture (2018). Norme tecniche per le costruzioni. Gazzetta Ufficiale della Repubblica Italiana 42, Decreo Ministero Infrastrutture 17.01.2018, Rome, Italy (in Italian).

Mollaioli F, AlShawa O, Liberatore L, Liberatore D, Sorrentino L (2018) Seismic demand of the 20162017 Central Italy earthquakes. Bull Earthq Eng Special Issue Central Italy Earthq. https://doi. org/10.1007/s10518-018-0449-y

Mucciarelli M, Liberatore M (2014) Guest editorial: the Emilia 2012 earthquakes, Italy. Bull Earthq Eng 12:2111-2116. https://doi.org/10.1007/s10518-014-9629-6

Newmark NM (1965) Effects of earthquakes on dams and embankments. Géotechnique 15(2):139-160. https://doi.org/10.1680/geot.1965.15.2.139 
Rampello S, Callisto L, Fargnoli P (2010) Evaluation of slope performance under earthquake loading conditions. Rivista Italiana di Geotecnica XLIV(4):29-41

Rathje EM, Abrahamson NA, Bray JD (1998) Simplified frequency content estimates of earthquake ground motions. J Geotech Geoenviron Eng 124(2):150-159

Rathje EM, Antonakos G (2011) A unified model for predicting earthquake-induced sliding displacements of rigid and flexible slopes. Eng Geol 122:51-60

Rathje EM, Cho Y (2019) Probabilistic assessment of the earthquake-induced displacements of a slope using finite element analysis. Proceedings of the 7th international conference on earthquake geotechnical engineering, Rome, Italy, 2019:209-220.

Rathje EM, Faraj F, Russell S, Bray JD (2004) Empirical relationships for frequency content parameters of earthquake ground motions. Earthq Spectra 20(1):119-144. https://doi.org/10.1193/1.1643356

Rathje EM, Saygili G (2008) Probabilistic seismic hazard analysis for the sliding displacement of slopes: scalar and vector approaches. J Geotech Geoenviron Eng 134(6):804-814

Rathje EM, Saygili G (2011) Estimating fully probabilistic seismic sliding displacements of slopes from a pseudoprobabilistic approach. J Geotech Geoenviron Eng 137(3):208-217

Rathje EM, Wang Y, Stafford PJ, Antonakos G, Saygili G (2014) Probabilistic assessment of the seismic performance of earth slopes. Bull Earthq Eng 12(3):1071-1090

Saade A, Abou-Jaoude G, Wartman J (2016) Regional-scale co-seismic landslide assessment using limit equilibrium analysis. Eng Geol 204:53-64

Sabetta F, Pugliese A (1996) Estimation of response spectra and simulation of non-stationary earthquake ground motions. Bull Seismol Soc Am 86(2):337-352

Sarma SK, Scorer MR (2009) The effect of vertical accelerations on seismic slope stability. In: Kokusho T, Tsukamoto Y, Yoshimine M (eds) Proceedings of the international conference on performance-based design in earthquake geotechnical engineering. Taylor and Francis Group, London, pp 889-896.

Saygili G, Rathje EM (2008) Empirical predictive models for earthquake-induced sliding displacements of slopes. J Geotech Geoenviron Eng 134(6):790-803

Scasserra G, Lanzo G, Stewart J, D’Elia B (2008) SISMA (site of Italian strong motion accelerograms): a web-database of ground motion recordings for engineering applications. AIP Conf Proc 1020(1):16491656. https://doi.org/10.1063/1.2963795

Seed HB (1979) Considerations in the earthquake-resistant design of earth and rockfill dams. Géotechnique 29(3):215-263. https://doi.org/10.1680/geot.1979.29.3.215

Stewart JP, Blake TF, Hollingsworth RA (2003) A screen analysis procedure for seismic slope stability. Earthq Spectra 19(3):697-712

Trifunac MD, Brady AG (1975) A study of the duration of strong earthquake ground motion. Bull Seismol Soc Am 65:581-626

Tropeano G, Silvestri F, Ausilio E (2017) An uncoupled procedure for performance assessment of slopes in seismic conditions. Bull Earthq Eng 15(9):3611-3637. https://doi.org/10.1007/s10518-017-0113-y

Tsai CC, Chien YC (2016) A general model for predicting the earthquake-induced displacements of shallow and deep slope failures. Eng Geol 206:50-59

Veylon G, Luu LH, Mercklé S, Bard PY, Delvallée A, Carvajal C, Frigo B (2017) A simplified method for estimating Newmark displacements of mountain reservoirs. Soil Dyn Earthq Eng 100:518-528

Wang Y, Rathje EM (2018) Application of a probabilistic assessment of the permanent seismic displacement of a slope. J Geotech Geoenviron Eng 144(6):04018034

Wilson RC, Keefer DK (1985) Predicting areal limits of earthquake-induced landsliding. In: Ziony ED (ed) Evaluating Earthquake Hazard in the Los Angeles Region. US Geological Survey, Reston, pp 317-345

Whitman RV, Liao S (1985). Seismic design of gravity retaining walls. In: Proceeeding of the 8th world conference. Earthquake engineering., Vol. 3, Earthquake engineering research institute staff, international association for earthquake engineering, San Francisco:533-540.

Yegian MK, Marciano EA, Ghahraman VG (1991) Earthquake-induced permanent displacement deformations: probabilistic approach. J Geotech Eng 117(1):35-50. https://doi.org/10.1061/ (ASCE)0733-9410(1991)117:1(35)

Publisher's Note Springer Nature remains neutral with regard to jurisdictional claims in published maps and institutional affiliations. 


\section{Affiliations}

D. Gaudio ${ }^{1,2}$ (D) R. Rauseo ${ }^{1} \cdot$ L. Masini $^{1}$ (D) S. Rampello ${ }^{1}$ (D)

R. Rauseo

rosanna.rauseo@gmail.com

L. Masini

luca.masini@uniroma1.it

S. Rampello

sebastiano.rampello@uniroma1.it

1 Department of Structural and Geotechnical Engineering, Sapienza University of Rome, Via Eudossiana 18, 00184 Rome, Italy

2 Present Address: Department of Engineering, University of Cambridge, Trumpington Street, Cambridge CB21PZ, UK 